\title{
Transcriptome dynamic landscape underlying the improvement of maize lodging resistance under coronatine treatment
}

Zhaobin Ren ${ }^{1+}$, Xing Wang ${ }^{1+}$, Qun Tao ${ }^{1 \dagger}$, Qing Guo ${ }^{1}$, Yuyi Zhou ${ }^{1}$, Fei $\mathrm{Y}^{1{ }^{*}}$, Guanmin Huang ${ }^{1}$, Yanxia Li ${ }^{1}$, Mingcai Zhang ${ }^{1}$, Zhaohu Li ${ }^{1}$ and Liusheng Duan ${ }^{1,2^{*}}$ (i)

\begin{abstract}
Background: Lodging is one of the important factors causing maize yield. Plant height is an important factor in determining plant architecture in maize (Zea mays L.), which is closely related to lodging resistance under high planting density. Coronatine (COR), which is a phytotoxin and produced by the pathogen Pseudomonas syringae, is a functional and structural analogue of jasmonic acid (JA).

Results: In this study, we found COR, as a new plant growth regulator, could effectively reduce plant height and ear height of both hybrids (ZD958 and XY335) and inbred (B73) maize by inhibiting internode growth during elongation, thus improve maize lodging resistance. To study gene expression changes in internode after COR treatment, we collected spatio-temporal transcriptome of inbred B73 internode under normal condition and COR treatment, including the three different regions of internode (fixed, meristem and elongation regions) at three different developmental stages. The gene expression levels of the three regions at normal condition were described and then compared with that upon COR treatment. In total, 8605 COR-responsive genes (COR-RGs) were found, consist of 802 genes specifically expressed in internode. For these COR-RGs, 614, 870, 2123 of which showed expression changes in only fixed, meristem and elongation region, respectively. Both the number and function were significantly changed for COR-RGs identified in different regions, indicating genes with different functions were regulated at the three regions. Besides, we found more than $80 \%$ genes of gibberellin and jasmonic acid were changed under COR treatment.

(Continued on next page)
\end{abstract}

\footnotetext{
*Correspondence: yifei56@cau.edu.cn; duanlsh@cau.edu.cn

${ }^{\dagger}$ Zhaobin Ren, Xing Wang and Qun Tao contributed equally to this work.

'State Key Laboratory of Plant Physiology and Biochemistry, Engineering Research Center of Plant Growth Regulator, Ministry of Education \&College

of Agronomy and Biotechnology, China Agricultural University, No.2

Yuanmingyuan West Road, Haidian, Beijing 100193, China

Full list of author information is available at the end of the article
}

(c) The Author(s). 2021 Open Access This article is licensed under a Creative Commons Attribution 4.0 International License, which permits use, sharing, adaptation, distribution and reproduction in any medium or format, as long as you give appropriate credit to the original author(s) and the source, provide a link to the Creative Commons licence, and indicate if changes were made. The images or other third party material in this article are included in the article's Creative Commons licence, unless indicated otherwise in a credit line to the material. If material is not included in the article's Creative Commons licence and your intended use is not permitted by statutory regulation or exceeds the permitted use, you will need to obtain permission directly from the copyright holder. To view a copy of this licence, visit http://creativecommons.org/licenses/by/4.0/ The Creative Commons Public Domain Dedication waiver (http://creativecommons.org/publicdomain/zero/1.0/) applies to the data made available in this article, unless otherwise stated in a credit line to the data. 
(Continued from previous page)

Conclusions: These data provide a gene expression profiling in different regions of internode development and molecular mechanism of COR affecting internode elongation. A putative schematic of the internode response to COR treatment is proposed which shows the basic process of COR affecting internode elongation. This research provides a useful resource for studying maize internode development and improves our understanding of the COR regulation mechanism based on plant height.

Keywords: Maize lodging, Coronatine, Plant height, Internode development, RNA-seq

\section{Background}

Maize, one of the three major food crops in the world, is consumed vast. However, the usable area for maize cultivation is gradually decreased every year. Facing the conflict, the major solution is to improve the yield per unit area, which can be realized by cultivating new varieties, increasing planting density and improving the farming condition. Among these approaches, the easiest way is to increase the planting density, but it brings the problem of lodging. Moderately reducing plant height is an effective strategy for improving lodging resistance in maize grown at high density. Meanwhile, the heavy rain and the strong winds, lead directly to the maize plants becoming flooded or lodged. Lodging leads to multiple adverse impacts, including the reduce of yield by $15-18 \%$, later maturing, quality reduction, harvest difficulty, aggravation in diseases, pests and rats $[66,106]$.

The plant height is generally positively correlated with lodging rate. Study the growth mechanism and plant height regulation of maize has great significance for improving lodging tolerance [107]. The plant height of maize is mainly determined by internode number and length particularly the 7th to 9th internodes, which are the usual occurrence of the stalk lodging for maize [68]. The internode can be divided into three parts during the elongation stage, including meristem region, elongation region, and fixed region [120].

The lower end of the elongating internode is the meristem, the region with active cell division. The elongation region is located above the meristem, where the cell expansion and primary cell walls formed [51, 95]. The fixed region, also known as the maturation region, is located at the upper end of the internode, in which the extended growth of cells is stopped and the deposition of secondary wall is main process [51]. Gene activity is closely associated with specific biological processes in these three type regions. It has been showed that the genes, which were related to gibberellin (GA) and auxin, mainly expressed in internode elongation region, such as dwarf1, dwarf3 and brachytic2 [12, 54, 102]. And NACs and $C A D$ genes which involve in regulating the secondary cell wall synthesis are mainly expressed in fixed regions $[15,39]$. Nevertheless, information on the transcriptional differences between meristem, elongation and fixed regions is far from clear.

The genes related to many hormones have been showed to be involved in the plant height, such as genes participated in biosynthesis, transport and signaling pathways of GA and jasmonic acid (JA) [16, 55, 97]. Some genes affect plant height by regulating GA synthesis and transduction, such as dwarf1, dwarf3, GA20oxs, GA3oxs, CPS, dwarf plant 8 and dwarf plant 9 [7, 73, 81, $83,101,102,108]$. JA affects plant height mainly via complex phytohormone crosstalk with GA and auxin. Studies showed that JA can affect the formation and distribution of auxin by inducing the ASA1 expression and regulating the PINs and PLETHORA [98], thereby affecting cell elongation. In addition, DELLAs, GA signal reverse regulation factor, can interact with the JA pathway to coordinate normal growth and defense to biotic stresses [110]. Therefore, phytohormones are of great significance to control internode development. However, the high production cost and the instability of molecular structure in the vitro environment make direct application of phytohormones very difficult in yield. Plant growth regulators, which are compounds with similar effects to phytohormones, overcome these difficulties $[105,112]$. Currently, the main component of plant growth regulators used in agriculture is 1,1-dimethylpiperidinium chloride (DPC) or ethephon [70, 121]. However, maize is not sensitive to DPC and the ethephon decreases grain yield of maize $[52,71]$. With the increase of planting density and mechanization level, a more efficient and safe new plant growth regulator is urgently needed.

Coronatine (COR), secreted by Pseudomonas syingae pathovars, is a phytotoxin $[46,50,76]$, with similar function as JA $[36,115]$. It has been showed that the COR is an analog of JA [100], and is 1000 times more active than JAs [93]. The COR can lead to adverse effects for plants, such as leaf chlorosis and disease symptoms [94]. However, COR of low concentrations can increase the abiotic stress resistance [40, 104, 124]. At present, COR can be produced by microbial fermentation, and has the advantages of lower environmental pollution and chemical residues. Therefore, as a new environmentally friendly plant growth regulator, COR is expected to be 
widely used in agriculture. Previous researches have shown that COR can inhibit the elongation of maize root, hypocotyl and mesocotyls [62]. Our previous studies have showed that COR had certain effect on reducing plant height $[85,99]$, while the molecular mechanism of COR in reducing plant height of maize is not well known.

In our study, the plant height of ZD958 and XY335, two wildly cultivated maize hybrids, could be significantly decreased under COR treatment via reducing internode length and thus improve lodging resistance. To research the underlying gene different expression that drive the responses of internode to COR, spatiotemporal transcriptome of inbred B73 internode were produced under control and COR treatment, containing the maturation, meristem and elongation regions of internode. The differences in transcription levels of the three regions at normal condition were displayed and then were compared with that upon COR treatment. In total, 8605 COR-responsive genes (COR-RGs) were reported, and internode specific genes accounted for 9.3\% (802 genes). For these COR-RGs, 614, 870, 2123 of which showed expression changes in only fixed, meristem and elongation region, respectively. Gene ontology enrichment analysis indicated that different genes in the three regions control their growth. Moreover, we found that $84 \%$ of GA related gens and $80 \%$ of JA related genes were significant affected under COR treatment. In summary, the differential expression map of gene expression response in internode to COR provides a theoretical support for future study of the molecular mechanism of plant height decreased by COR.

\section{Results}

The plant height of maize is significantly decreased under COR treatment

We found that the plant height of ZD958 and XY335, two wildly cultivated maize hybrids, were significantly decreased under the treatment of exogenous COR $(10 \mu \mathrm{M})$ at the stage with nine leaves, which average decrease of about $5 \mathrm{~cm}$ (Fig. 1a; Additional Fig. $1 \mathrm{~A}$ and Additional Data Sets 1). The grain weight per plant displayed no significant change but the yield can be increased due to lower lodging rate under COR treatment as compared with untreated controls in the field (Fig. 1b, c; Additional Fig. $2 \mathrm{~A}$ and Additional Data Sets 1). To explore the mechanism of decrease of plant height of maize under COR treatment, we performed the COR treatment at the ninth leaf stage for B73 inbred, which the reference genome was available [48] growing in the greenhouse. The length of 7 th internode was not affected due to it was elongated completely before COR treatment, but the elongation of 9th internode was significantly inhibited in 2 days later after COR treatment
(Fig. 1d; Additional Fig. 1 B and Additional Data Sets 1). Finally, the length of 9th internode was decreased about $8.1 \%$ (average from $13.96 \pm 1.75 \mathrm{~cm}$ to $12.83 \pm 1.50 \mathrm{~cm}$ ) (Fig. 1e; Additional Data Sets 1). At maturity, the plant height was decreased from $205 \pm 16.56 \mathrm{~cm}$ to $188.4 \pm$ $14.31 \mathrm{~cm}$ and ear height was decreased from $93.85 \pm$ $11.21 \mathrm{~cm}$ to $84.10 \pm 10.10 \mathrm{~cm}$, respectively, for B73 inbred treated by COR (Fig. 1g, h and i; Additional Data Sets 1). Besides, we found the fracture resistance of the 9th internode was significantly increased under COR treatment (average from $459 \pm 9.63 \mathrm{~N}$ to $520.3 \pm 11.44 \mathrm{~N}$ ) (Fig. 1f; Additional Data Sets 1), which might due to more lateral cell number in the internode cortex (Additional Fig. 2 B). Taken together, COR was a new plant growth regulator which could effectively reduce plant height and ear height of maize by inhibiting cell elongation during internode elongation stage, thus beneficial to improve maize lodging resistance.

\section{The generation of spatio-temporal transcriptomes of maize internode under normal conditions and COR treatment}

To explore the mechanism of plant height reduction of maize under COR treatment, we used the RNA-seq to study the transcription level of genes of the fixed region (F) of 7 th internode, and the meristem region $(\mathrm{M})$ and elongation region (E) of 9th internode collected in 1st, 2nd, and 4th day after COR treatment (at the stage with nine leaves) (Fig. 2a). For the convenience of subsequent description, which were named as F1_T (treatment), F2 T, F4_T, M1_T, M2_T, M4_T and E1_T, E2_T, E4_T, respectively. Corresponding control which were collected at normal growth conditions were named as F1_C (control), F2_C, F4_C, M1_C, M2_C, M4_C and E1_C, E2_C, E4_C, respectively. In totally, 3.24 billion reads were obtained by the Illumina sequencer, and average 92.41\% (Additional Table 1) of which could be uniquely mapped to the maize reference genome of B73 (RefGen V4) [48] by Hisat2 [53]. The normalized gene expression value was descripted by calculating the fragments per kilobase of transcript per million mapped reads (FPKM) on the strength of uniquely mapped reads. The expression level of each sample is descripted by the average FPKM values of two biological replicates because the correlation coefficient of them was high (average value of $R^{2}$ was more than 0.93, Additional Fig. 3). To reduce the error caused by transcription noise, here only genes which FPKM values were larger than 1 were defined as expressed genes. In total, the expressed genes were 24, 048 (including 1400 transcription factors (TFs)), which had expression in at least one of the 18 samples (Additional Data Sets 2).

The principal component analysis (PCA) result showed that the 18 samples were generally grouped into 

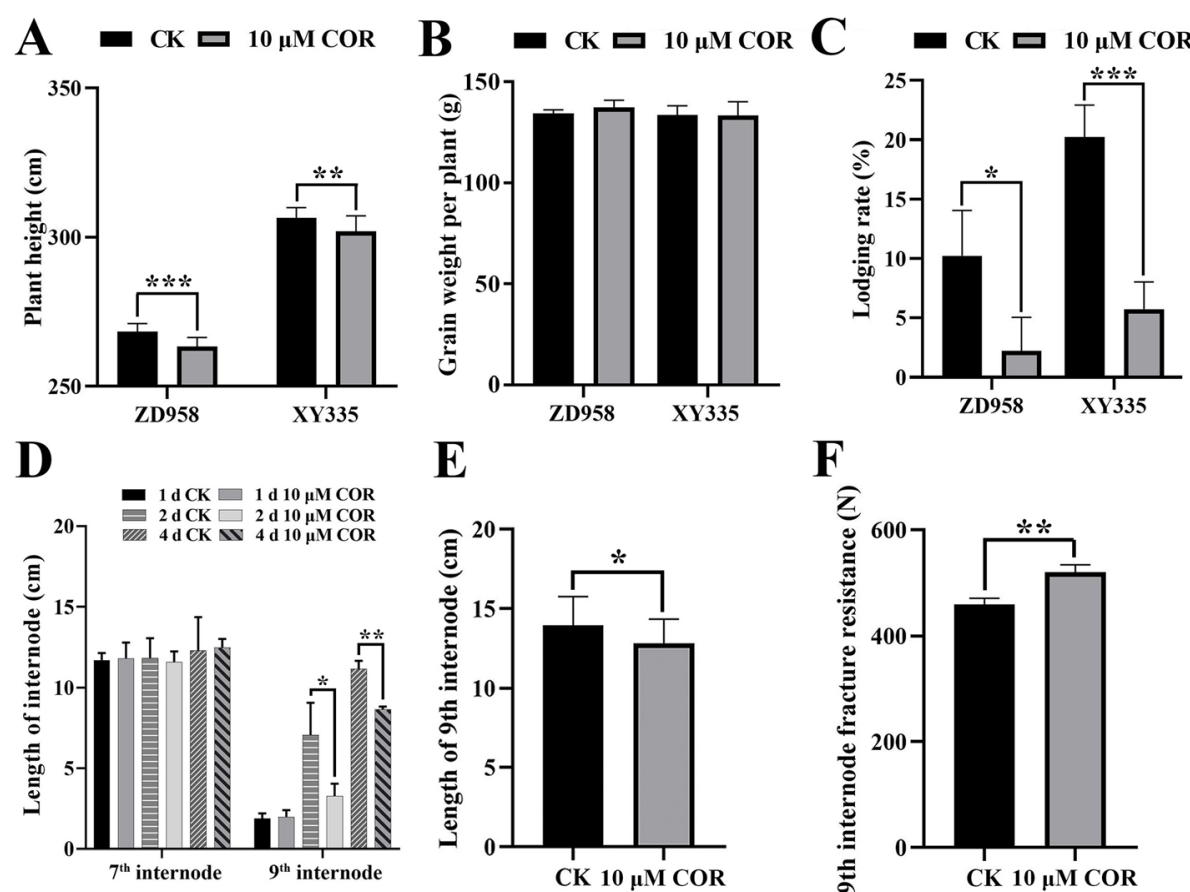

$\mathbf{F}$
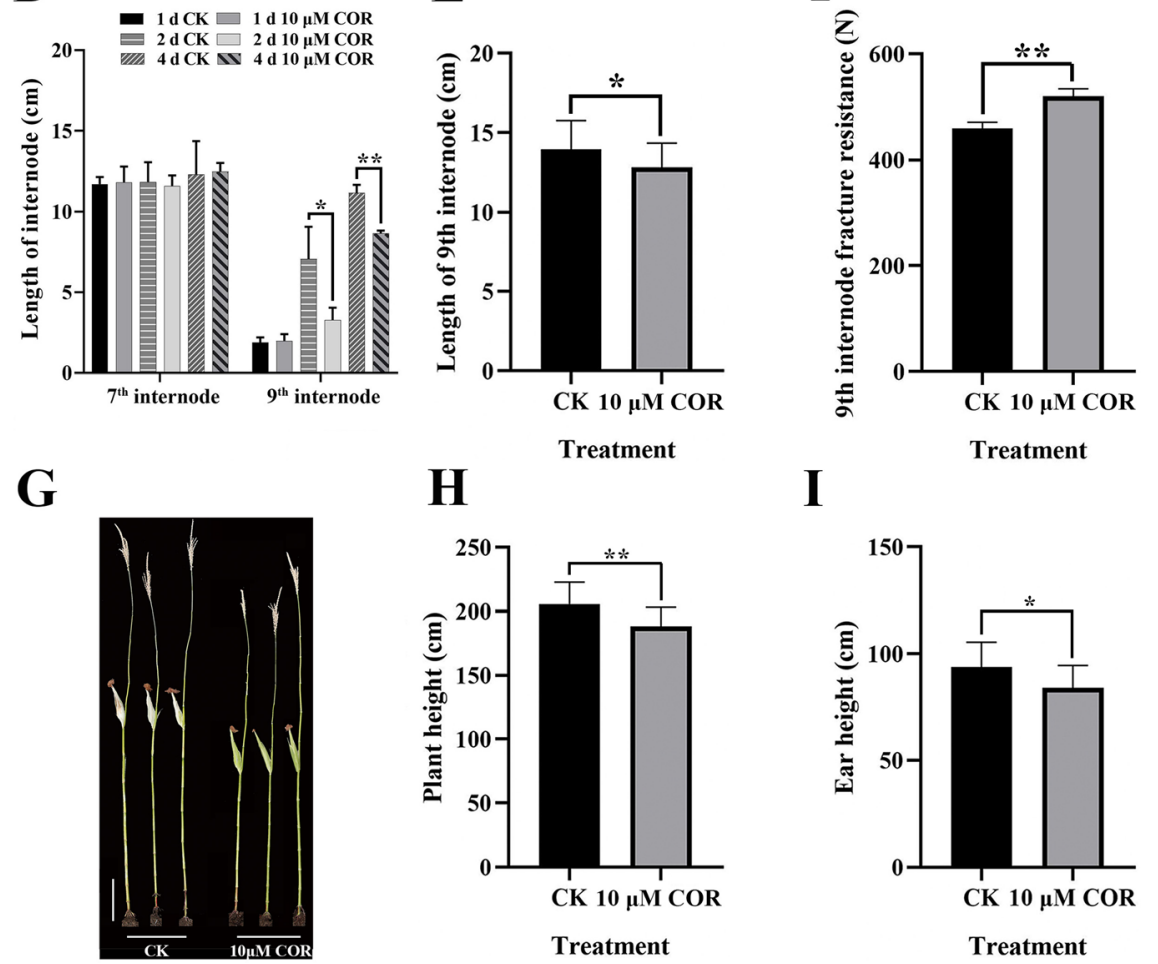

I
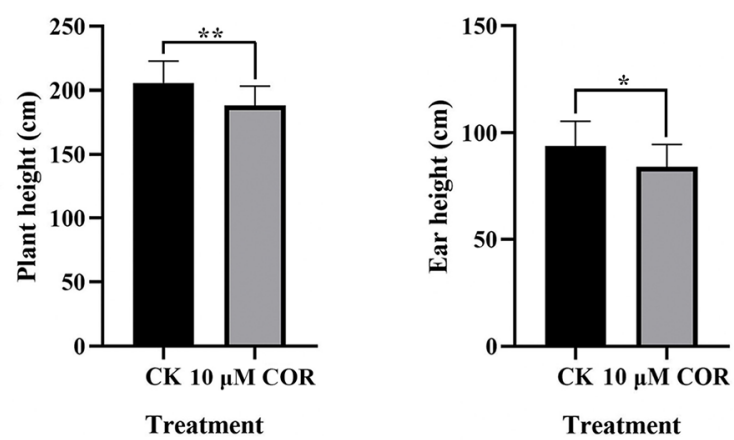

Fig. 1 The decrease of plant height of maize under COR treatment. a Comparison of the plant height of ZD958 and XY335 with and without COR treatment. The data were presented as means \pm SE $(n=15)$. Error bars indicate SE. ${ }^{* *}: 0.001<p$-value $<0.01 ;{ }^{* * *}: p$-value $<0.001$. $\mathbf{b}$ Comparison of the grains weight per plant of ZD958 and XY335 with and without COR treatment. No significant change was observed. The data were presented as means \pm SE $(n=124)$. Error bars indicate SE. c Comparison of the lodging rate of ZD958 and XY335 with and without COR treatment. This experiment uses four biological replicate designs for the two maize hybrids. At least 33 plants were collected in each replicate. *: $0.01<p$-value $<0.05 ;{ }^{* * *}: p$-value $<0.001$. d Comparison of the length of 7 th internode and 9 th internode of B73 with and without at the three time points. The data were presented as means \pm SE $(n=3)$. Error bars indicate SE. ${ }^{*}: 0.01<p$-value $<0.05 ;{ }^{* *}: 0.001<p$-value $<0.01$. e Comparison of the finally length of 9 th internode of B73 with and without COR treatment. The data were presented as means \pm SE $(n>23)$. SE is represented by error bars. *: $0.01<p$-value $<0.05$. $\mathbf{f}$ Comparison of the fracture resistance of 9th internode of B73 with and without COR treatment. The data were presented as means \pm SE $(n=3)$. Error bars indicate SE. **: $0.001<p$-value $<0.01$. g Gross morphologies of B73 with and without COR treatment. Scale bars, $30 \mathrm{~cm}$. $\mathbf{h}$ Comparison of plant height of B73 with and without COR treatment. The data were presented as means \pm SE $(n>15)$. SE is represented by error bars. ${ }^{*}: 0.001<p$-value $<0.01$. i Comparison of ear height of B73 with and without COR treatment. The data were presented as means \pm SE $(n>15)$. SE is represented by error bars. *: $0.01<p$-value $<0.05$.

three categories, with each category corresponding to a specific internode region, and the COR treated and untreated samples can be separated well (Fig. 2b). In order to further increase the credibility of transcriptional results we obtained, we checked the expression patterns of 12 marker genes, which their expression regions were previously reported. ZmIncw1, ZmNAC109, ZmMYB32, and $Z m I R X 9$ are genes involved in sugar transport, and lignin synthesis process, and were shown to be highly expressed in the fixed region [17, 42, 69, 120, 121] (Fig. 2c). ZmGSL1, ZmGRFTF1, ZmCslA1, and ZmEXPA2, related to cell division and cell wall biosynthesis, were 
A

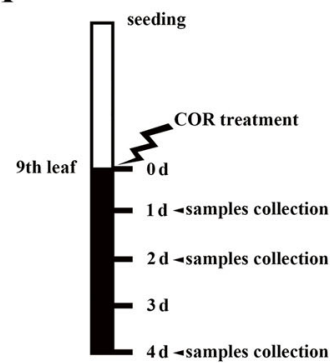

$c^{c}$

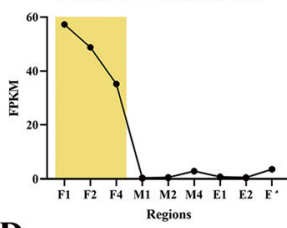

D RmGSL1 Zm00001d038056

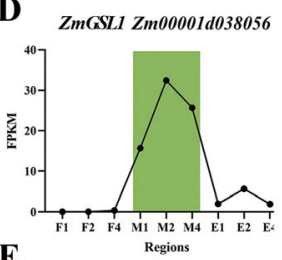

E

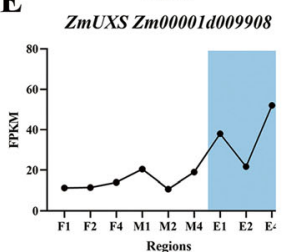

F ${ }_{Z M P A L 2 Z m 00001 d 003016}$

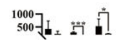

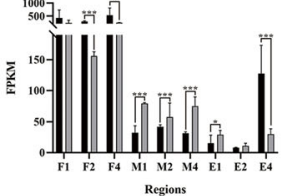

G

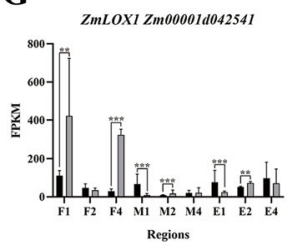

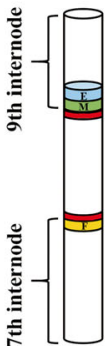

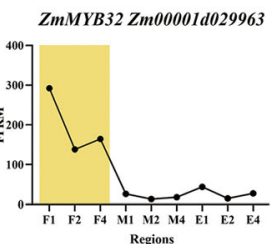

ZmGRFTF1 Zm00001d033876

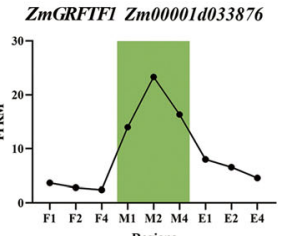

Regions

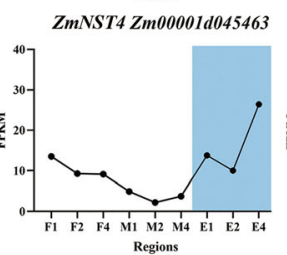

ZmPAL3 Zm00001d051161

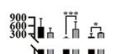

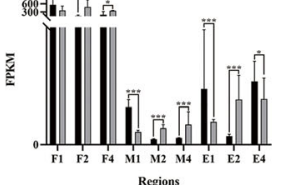

Regions

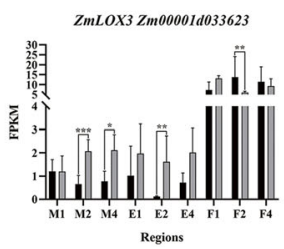

B
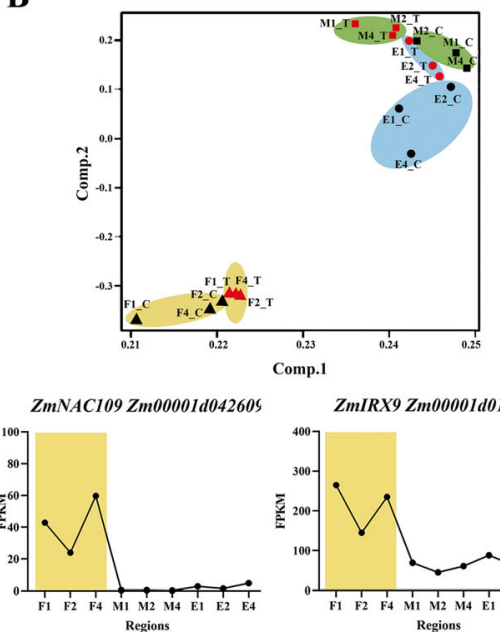

ZmCslA1 Zm00001d053696
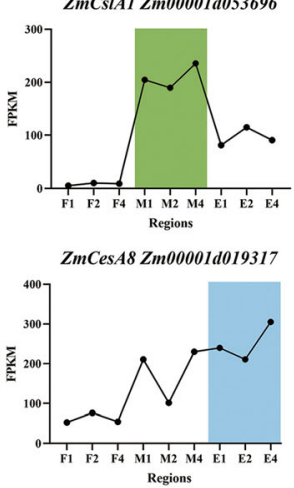

ZmPAL5 Zm00001d051163
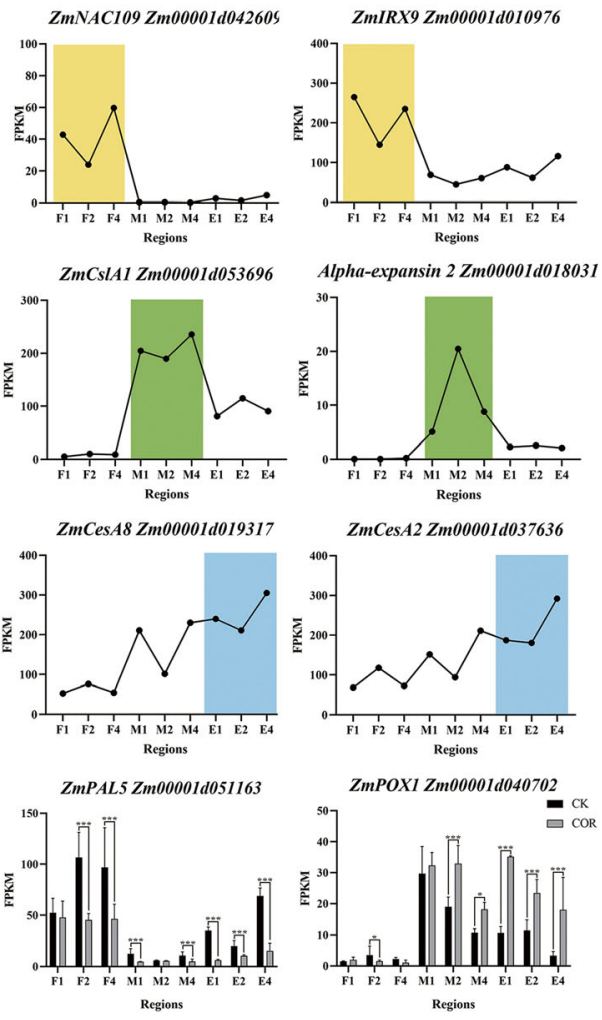

Alpha-expansin 2 Zm00001d018031

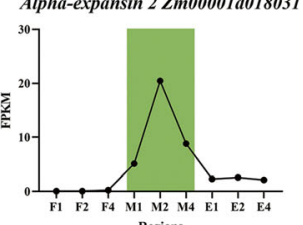

Regions

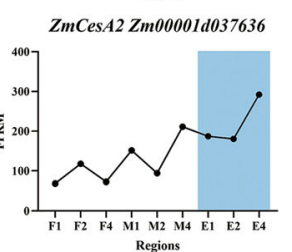

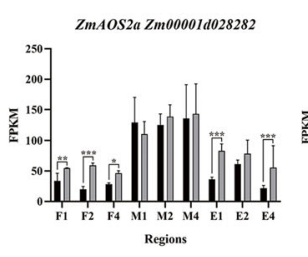

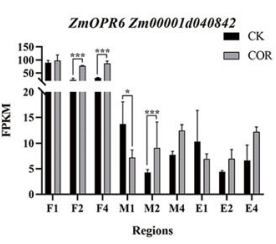

Fig. 2 Sampling diagram and transcriptomic data quality analysis. a The cartoon showed sampling time points and regions of internode. The maize was treated with $10 \mu \mathrm{M} C O R$ when the 9th leaf was fully expanded. The fixed region ( $F$, apical $1 \mathrm{~cm}$ of the internode) of 7 th internode, and the meristem region ( $M$, basal $0-1 \mathrm{~cm}$ between internode) and elongation region ( $E$, basal $1-2 \mathrm{~cm}$ between internode) of 9th internode collected in 1st, 2nd, and 4th day later after COR treatment. b Principal component analysis (PCA) of 18 samples. $\mathbf{c}$ to e The region-specific expression genes mainly expressed in the region of fixed $(\mathbf{c})$, meristem $(\mathbf{d})$ and elongation $(\mathbf{e})$ region. The region of fixed region, meristem region and elongation are display in light yellow, blue and green, respectively. $\mathbf{f}$ and $\mathbf{g}$ The expression of COR-induced genes. These genes are related to plant defense (f) and JA pathway (g) were showed. *: $0.01<p$-value $<0.05$; **: $0.001<p$-value $<0.01$; $^{* * *}$ : $p$-value $<0.001$

shown to have highly expression in the meristem region [65, 117, 125] (Fig. 2d). ZmUXS (UDP-xylose synthase), ZmNST4, ZmCesA8, and ZmCesA2, involved in cell wall biosynthesis, were highly expressed in the elongation regions $[2,103,117]$ (Fig. 2e). The preference of the expressions of these 12 marker genes in our results were consistent with previously reports, which indicated that the fixed region, meristem region and elongation region samples were collected well. 
In addition, we found that ZmPAL2, ZmPAL3, $Z m P A L 5$, and $Z m P O X 1$, four genes related to defense processes in maize $[26,82]$, and $Z m A O S 2 a, Z m L O X 3$, $Z m L O X 1$ and $Z m O P R 6$, involved in JA signaling pathway $[30,93]$, showed significant differentially expression after COR treatment (Fig. 2f, g). This was in line with that COR is not only a phytotoxin by $P$. syringae but also an analog of JA. In total, our spatio-temporal transcriptomes, which generated for maize internode with or without COR treatment, is high quality and accuracy.

\section{Expression profiling of internode under normal conditions}

The spatio-temporal transcriptomes generated here provided us a good opportunity to character the specific expression features of fixed, meristem and elongation regions of maize internode before exploring the effect of COR on transcription of internode.

Totally, 23,349 expressed genes were detected in internode tissues collected in normal condition, including 1357 (5.81\%) TFs (Fig. 3a; Additional Data Sets 3). These genes were classified into 14 co-expression types by the k-means clustering algorithm. The genes (9776 genes, including 472 TFs) in four modules of which were found with expression at more than one of the three regions of internode (Fig. 3a) indicating the common functional processes in different tissue types of internode regions. Interestingly, there were $58 \%(13,573)$ of genes (belonged to eleven modules) mainly expressed at only one of the three different tissues of internode, reflecting the big difference among the fixed, meristem and elongation regions of internode.

\section{Genes mainly expressed in the fixed region $(F)$}

The fixed region of internode was best represented by 7777 expressed genes, including 616 TFs in the module F-I to F-V (Fig. 3a; Additional Data Sets 3). The genes of module F-I (961 genes, 66 TFs), F-II (855 genes, 46 TFs), and F-III (855 genes, 54 TFs) were mainly expressed at 1st, 2nd, 4th day, respectively, and the genes in module F-IV (1509 genes, 188 TFs) were mainly expressed at 1st and 4th but not in 2nd day, reflecting the transcriptional dynamic during the development of fixed tissue. In addition, there were 3597 genes

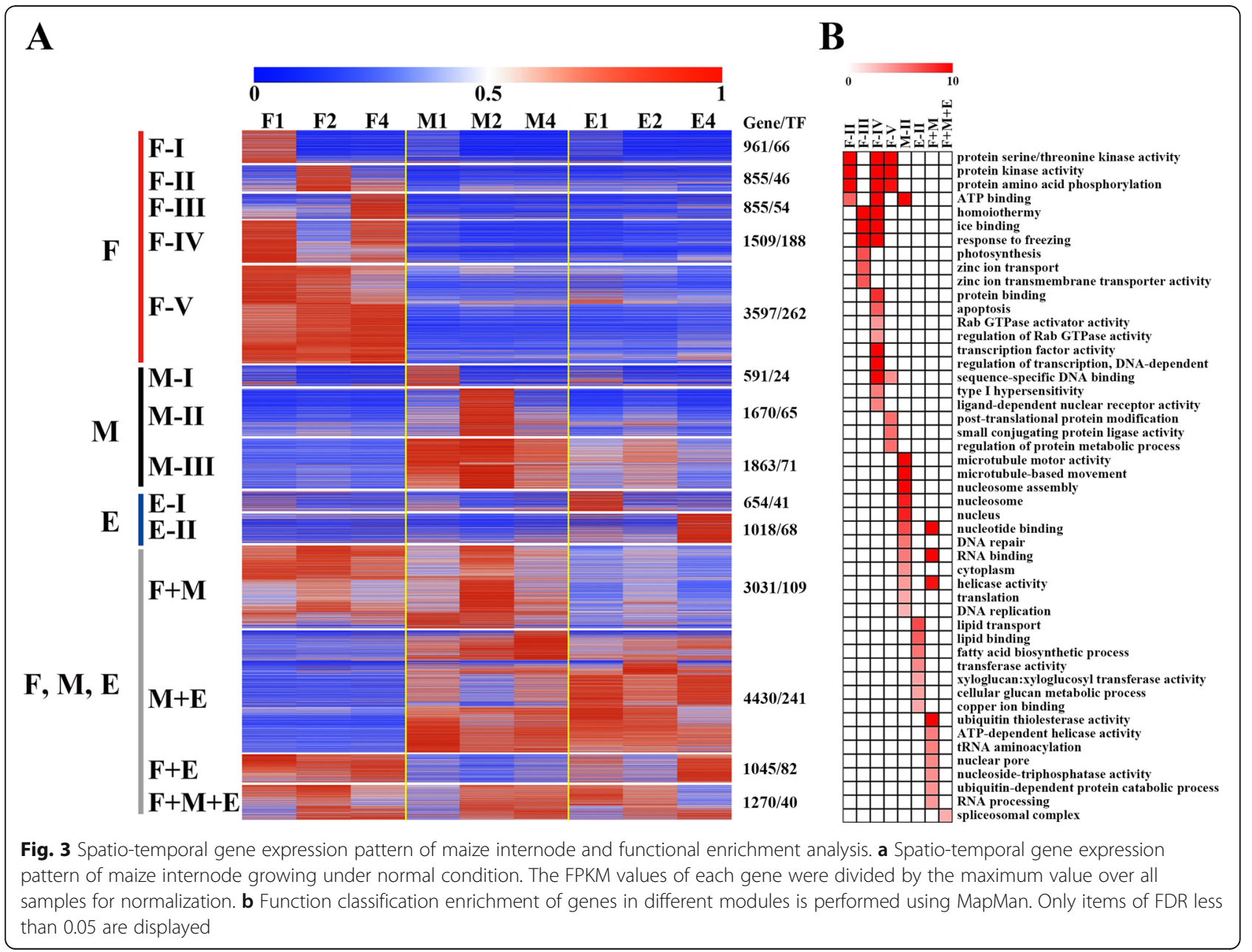


(including 262 TFs) in module F-V showed continuity expression at the three points of fixed tissue development. Gene annotation analysis showed that these fixed regions associated modules were mainly overrepresented with genes involved in protein kinase activity, amino acid phosphorylation, ATP binding etc. (Fig. 3b). A recent study showed that the increase of ethylene level could favor cell wall synthesis and deposition at fixed region of mature internodes [120, 121]. Consistent with this, there were 17 ethylene pathway genes were highly expressed in the module F-I, including 11 ethyleneresponsive element binding protein (EREBP) transcription factors (ZmEREB23, ZmEREB54, ZmEREB97, $Z m E R E B 104$ et al.), one 1-aminocyclopropane-1-carboxylate oxidase $(Z m A C C O 20)$, two ethylene receptors (ZmERS14 and ZmETR40), one gene encoding 1aminocyclopropane-1-carboxylate synthase (ZmACS6), one tasseled gene (ZmTS6) and one bHLH transcription factor (Zmpco106446).

\section{Genes mainly expressed in the meristem region (M)}

The 4124 expressed genes in module M-I to M-III, including $160 \mathrm{TFs}$, were best show the gene expression pattern of internode meristem region (Fig. 3a; Additional Data Sets 3). The most typical characteristic of meristem region is with vigorous cell division. According to this, the module M-II genes (1670 genes including $65 \mathrm{TFs}$ ) were mainly involved in division related processes, including microtubule motor activity, microtubule-based movement, nucleosome assembly, nucleotide binding, helicase activity, DNA replication and repair (Fig. 3b). For example, genes encoding RAD51D and SPO11 family proteins, which were related to DNA replication process [58, 72], and genes encoding cyclin family proteins (such as cyclin D1), which were related to G2 phases of cell division [41], were included in module M-II. In addition, the 591 genes of module M-I, including 24 TFs, were mainly expressed in meristem region at 1st day. ZmRAF1, a gene can increase the Rubisco content, and ZmPPD1 and $Z m Y C F 3$, two genes can increase the photosynthesis capacity of maize [74, 111], were included in module M-I. This might reveal the need of large amount of organic material synthesis in meristem before entering into stage with vigorous cell division. The genes of module M-III (1863 genes, $71 \mathrm{TFs}$ ) were expressed in meristem at all three time points. The genes related to energy and hormone signal transduction were found in this module. Such as ZmTIDP3692 and ZmZIM20 play roles in glycolytic pathway and cell number. They play an important role in energy supply and cell division, respectively [1, 79] might play an indispensable role in the meristem.
Genes mainly expressed in the elongation region (E)

The genes of module E-I and E-II represents the specific gene transcription level of the internode elongation region (Fig. 3a; Additional Data Sets 3). Genes in module E-I (654 genes, including $41 \mathrm{TFs}$ ) and E-II (1018 genes, including $68 \mathrm{TFs}$ ), were mainly expressed in the elongation region at 1 st and 4 th day, respectively. $Z m R O P 2$ and $Z m R O P 9$, which are involved in early phase of directional cell expansion [28], ZmCA5P9, which is related to cell elongation $[4,28,122]$, and $Z m A B I 20$, a B3 domaincontaining protein might associated with the stem elongation through affecting GA synthesis [38], were also found in module E-I. The module E-II are overrepresented with genes related to lipid transport, lipid binding, fatty acid biosynthetic process, transferase activity, xyloglucosyl transferase activity, cellular glucan metabolic process and copper ion binding (Fig. 3b). Three beta-expansin genes (ZmEXPB5, ZmEXPB6 and $Z m E X P B 7)$, which is associated with the synthesis of the primary wall [57], and four cellulose synthase genes (ZmCesA1, ZmCesA2, ZmCesA4 and ZmCesA9) [117] were included in module E-II. Taken together, these results suggested that the genes in module E-I and E-II were closely associated with vigorous cell elongation in the elongation region of internode. In addition, some NACs and MYBs related to cell wall biosynthesis were specifically expressed in this module, such as ZmNAC92, $Z m N A C 86, Z m M Y B 23$ and ZmMYB27 [120, 121].

\section{Transcriptional disturbance of internode under COR treatment}

To identify genes exhibiting responses to the COR treatment, each of nine COR treated samples were compared with their corresponding control samples without COR. Finally, a total of 8605 genes including 490 TFs were found with significantly different expression between at least one of the 9 sample pairs at the threshold of the 5\% false discovery rate (FDR) and more than 2 fold changes, and were designated as COR-responsive genes (COR-RGs) (Additional Data Sets 4). For these COR-RGs, 3165, 5226 and 6664 of which were identified in the fixed, meristem and elongation regions, respectively. These genes were classified using Venn diagram (Fig. 4), which showed that there were $614,870,2123$ COR-RGs specifically found in the fixed, meristem and elongation regions, respectively, and only 1452 ( $16.9 \%$ of all COR-RGs) showed different expression in all three type regions of internode. These results reflected the varied effect of COR on different tissue types. Relatively more serious influence of COR on non-fixed tissues, especially for elongation region, was consistent with the observation of plant height decrease under COR treatment. 


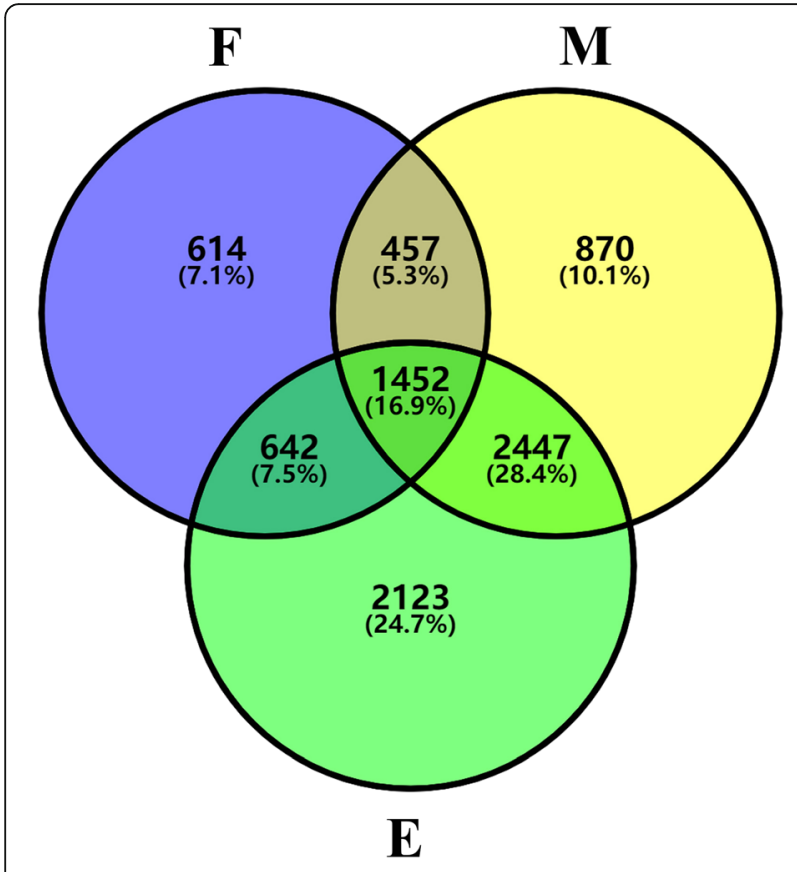

Fig. 4 Analysis of COR-RGs identified in different regions of internode. Venn diagram of the 8605 COR-RGs detected among fixed, meristem and elongation regions

\section{COR-RGs specifically identified in fixed region of internode}

The COR-RGs specifically identified in fixed region were categorized into two groups: up-regulated on fixed regions (F-up COR-RGs) and down-regulated on fixed regions (F-down COR-RGs), which contained 327 genes (including 15 TFs) and 287 genes (including 27 TFs), respectively (Fig. 5a; Additional Data Sets 4). Gene ontology (GO) enrichment analysis indicated that genes involved in iron ion binding, lipid metabolic process and oxidation reduction were overrepresented in F-up COR-RGs, while genes involved in protein kinase activity and amino acid phosphorylation were overrepresented in F-down COR-RGs (Fig. 5b), including many stress tolerance related genes. Up-regulation of JA signal pathway related genes was associated with enhancement of stress tolerance in maize as reported recently [10, 34]. And we found $Z m L O X 5, Z m L O X 6$, $Z m L O X 10, Z m A O S 1, Z m A O S 3$, which were related to lipid metabolic process and response to JA [13, 14, 30] were up-regulated in fixed region after COR treatment. ZmPSEI7 is a gene encoding cysteine proteinase inhibitor, which the expression can improves the maize insect resistance $[10,49,80]$, was also up-regulated in fixed region after COR treatment. In addition, we found the expression of $Z m P O X 3$ and $Z m C Y P 11$, which are two genes related to tetrapyrrole pathway and their high expression is not conducive for plant resistance to biotic stress [27, 37, 84], were down-related in fixed region after COR treatment.

\section{COR-RGs specifically identified in meristem region of} internode

The COR-RGs specifically identified in meristem region were contained by 328 up-regulated genes (M-up CORRGs, including 23 TFs) and 542 down-regulated genes (M-down COR-RGs, genes, including 42 TFs) (Fig. 5a; Additional Data Sets 4). The M-up COR-RGs were mainly related to cell cycle, such as regulation of cell cycle and cell cycle checkpoint. ZmCKI4 encodes a cyclin-dependent kinase inhibitor which can inhibit the cell division [31], and ZmKRP1 is a cyclin-dependent kinase inhibitor which can inhibit the cell size number and cell division [77]. Up-regulation of these two genes suggested that the activity of cell division was generally reduced in meristem region of internode, consistent with the decrease of plant height with COR treatment. According to the reduction of activity of cell division, the genes related to cellulose biosynthetic process, membrane and transmembrane transport were downregulated in meristem region (Fig. 5b). For example, many CesA family genes, including $Z m C e s A 1, Z m C e s A 4$, $Z m C e s A 6, Z m C e s A 7$ and $Z m C e s A 9$, which are closely associated with cellulose synthesis of cell walls and can affect cell elongation, were identified as M-down CORRGs. In addition, ZmTRPS1, a gene which can decrease cell division through altered cell wall structure [2, 29, 54], and $Z m B R 2$, a green revolution gene which affects the transmembrane transporter activity and its low expression can lead to decrease of plant height [64], was also down-regulated in meristem region of internode after COR treatment. Overall, there results reflected an inhibitory effect of COR effect on cell division in meristem regions.

\section{COR-RGs specifically identified in elongation region of internode}

The COR-RGs specifically identified in elongation region of internode, which contained 1281 up-regulated genes (E-up COR-RGs, including 23 TFs) and 842 downregulated genes (E-down COR-RGs, genes, including 80 TFs) (Fig. 5a; Additional Data Sets 4), was far more than that specifically identified in fixed or meristem regions of internode. The E-up COR-RGs were enriched with genes related to the regulatory activity (e.g., catalytic activity, nucleotide and RNA binding, and RNA processing), translation (e.g., ribosome, translational elongation) and cell structure establishment (e.g., nucleosome assembly) (Fig. 5b). Previous studies showed that ZmGRAS19 and ZmGRAS58 can disturb cell elongation through affecting the formation of secondary walls, cell proliferation and cell differentiation [56], and ZmDCL101, ZmDCL104 and ZmDCL105, which encode DCL family proteins, are related to defense process and plant height [19, 89], and ZmGST10, ZmGST16 and 


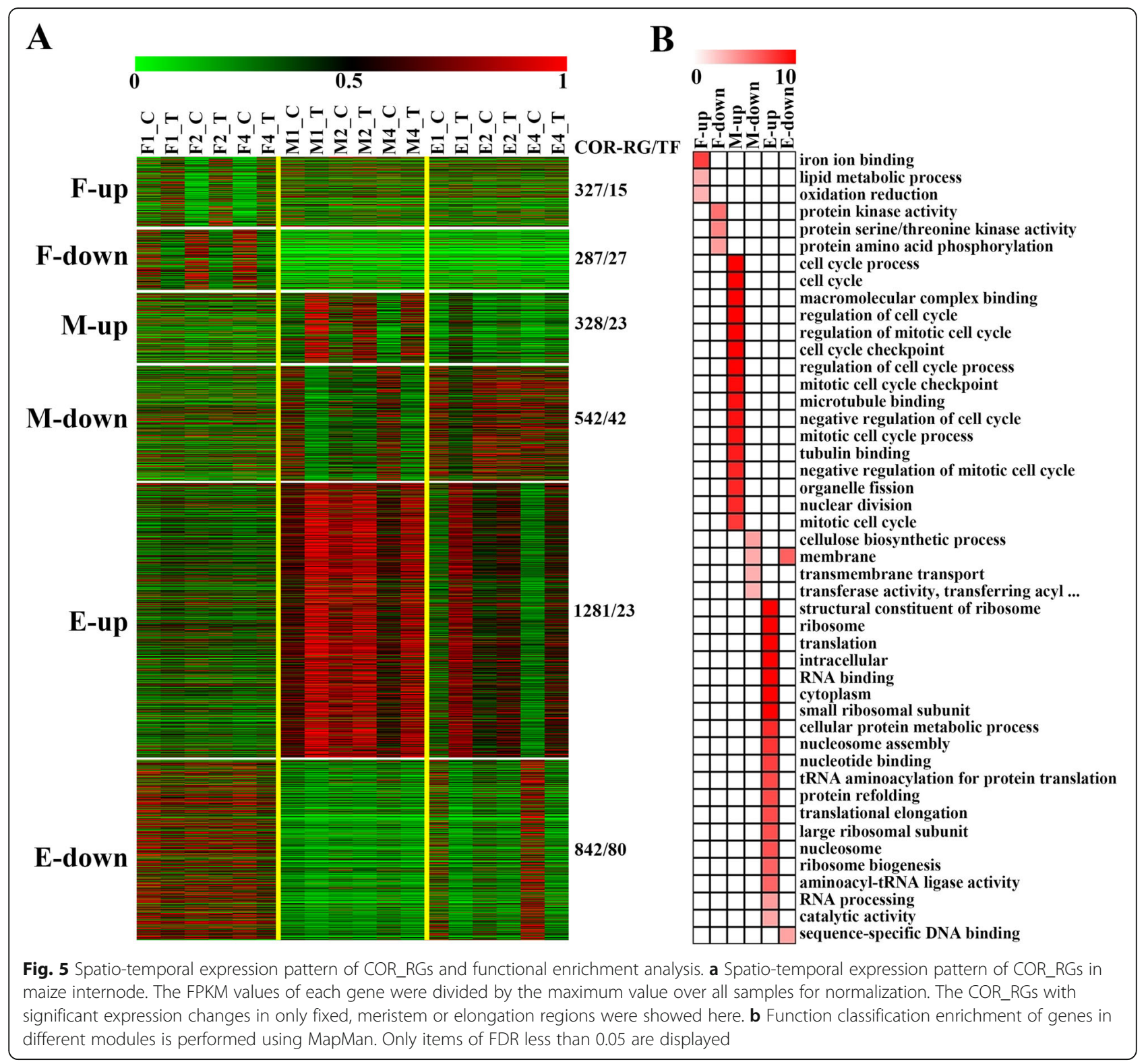

ZmGST22, which encode the glutathione transferases, are related plant defense process [21]. Here we found all these eight genes were grouped in grounded E-up CORRGs. In addition, we found some genes which expressions were positively associated with cell elongation were downregulated in elongation region of internode. For example, $Z m C e s A 10, Z m C e s A 12$ and $Z m C e s A 13$, three cellulose synthase genes which the reduce of expression can inhibited cell elongation $[2,24]$, were down-regulated. In addition, we found that genes related to response to GA, such as ZmGID1 and ZmGID2 [123], were also down-regulated after COR treatment, consistent with the inhibit of cell elongation. Overall, the indicating the defense process was activated and the vegetative growth was inhibited for elongation region of internode after COR treatment.

\section{COR-RGs identified in more than one of the three regions of} internode

Besides genes with repose specific in fixed, meristem or elongation regions of internode, there also have a lot of genes $(4998,58.1 \%$ of total COR-RGs) showed repose in more than one of the three type regions after COR treatment (Additional Fig. 4). A mainly category is genes (2447) with repose in both meristem and elongation regions but not in fixed regions, in line with the close association of meristem and elongation regions with internode length. There were 1245 genes (including 53 $\mathrm{TFs}$ ) up-regulated in meristem and elongation regions, which mainly related to cell division, such as nucleosome assembly, helicase activity, nucleosome, DNA replication and microtubule motor activity (Additional Fig. 
4B), and 1202 genes (including $95 \mathrm{TFs}$ ) down-regulated in meristem and elongation regions, which are mainly involved in protein kinase activity, lipid metabolic process, glycosyl groups transferase activity, transcription regulator activity and transferase activity, transferring acyl groups other than aminoacyl groups (Additional Fig. 4B). According to inhibit of cell divide in meristem region and cell elongation in elongation region, the expressions of ZmTHX43 and ZmIRX15 which are associated with xylan biosynthesis and $Z m \operatorname{Ces} A 8$ a constituent of secondary cellulose synthase complexes responsible for cellulose synthesis after cell expansion completion [5, 9, 22, 25], were down-regulated. In addition, we found some genes involved in the auxinactivated signaling pathway, such as ZmARF7 and ZmIAA11 [67], were also down-regulated in meristem and elongation regions.

\section{Internode specific genes with response after COR treatment}

The spatio-temporal transcriptome data generated here gave us a good opportunity to identified internode specific genes via combined with the promulgated RNA-seq data of different maize tissues, including leaf, tassel, root, cob, silks, endosperm, pericarp, seed, ear, embryo, and anthers $[18,23,59,63,96]$. Totally, we identified 1376 genes (including $70 \mathrm{TFs}$ ) with specific expression in internode (Additional Fig. 5; Additional Data Sets 5). In these internode specific genes, $58.3 \%$ of which $(802$ genes, including $37 \mathrm{TFs}$ ) were belonged to COR-RGs (Additional Data Sets 6), significantly higher than the proportion of total expressed genes accounted by CORRGs (35.8\%), indicating the overrepresentation of internode specific genes in COR_RGs. For these COR-RGs specifically expressed in internode, 427 of which were up-regulated and 375 of which were down-regulated. Grouping according to the regions with expression change, we found 200 internode specific COR_RGs, taking $24.94 \%$ of total, were up-regulated in all the three type regions of internode. These $\mathrm{F}+\mathrm{M}+\mathrm{E}$-up internode specific COR_RGs were enriched with genes related to triose-phosphate isomerase activity (Additional Fig. 6A, B), such as ZmTpi1 and ZmIPS1 (Inositol-3-phosphate synthase) which the expression can initiate the defense mode of plant $[47,61]$. In addition, $Z m S D H$ (succinate dehydrogenase) and $Z m T H 1$, which are related to the induction of oxidative stress $[6,92]$ are also identified as $\mathrm{F}+\mathrm{M}+\mathrm{E}$-up internode specific COR_RGs. These results suggested that some defensive reactions were common among the three type regions of internode after CORtreatment. In addition, we found internode specific genes ZmPGP9 which can promote inhibits auxin transport [32], ZmARR7 which the reduce of expression is benefit for improving the defense ability of maize [45], and $Z m A B I 32$ which the reduce of expression is favor for drought resistance of plants [78], were specifically down-regulated in fixed, meristem and elongation region, respectively. And the ZmIAA41 genes which related to the auxin signal was down-regulated in both fixed and elongation regions, consistent with the report that the reduce of its expressions can inhibit cell expansion and lead to plant dwarfing $[109,118]$.

\section{Differential expression of phytohormone-related genes under COR treatment}

The plant growth and development are regulated by a complex plant hormone crosstalk, while ABA, IAA, GA and JA are critical components in these processes [35, 75]. We first studied the regulation of COR on ABA, IAA, GA and JA related genes. Totally, we found 34 $A B A$ related genes were expressed in our data and the expression of $47 \%$ (16) genes could be significantly affected by COR. In this research, 169 IAA related genes were expressed and the expression level of 52\% (88) genes could be significantly affected by COR. 74 GA related genes were expressed in this research and the expression value of $84 \%$ (62) genes could be significantly affected by COR. And 35 JA related genes were expressed in this article, the expression of $80 \%$ (28) genes were significantly affected by COR. The results showed that the COR-RGs proportion of GA $(84 \%)$ and JA (80\%) were significantly greater than those of ABA (47\%), IAA (52\%) and all genes (36\%) (Additional Fig. 7). Then we focused on the regulation of COR on GA and JA related genes.

\section{Effect of COR on genes of GA pathway}

GA, a phytohormones of tetracyclic diterpenoid, plays essential roles during plant growth process. Among the 62 significant differentially expressed genes under COR treatment, most of the genes showed significant downregulation in the meristem region and elongation region. It consistent that reduced GA biosynthesis and suppression of GA signaling pathways lead to reduced plant height and internode shortening [3]. It's worth noting that three famous green revolution genes $Z m D 3$, $Z m G A 20 o x 2$ and ZmGA20ox3 [73, 102] which are affecting GA biosynthesis were down-regulated in the elongation region after COR treatment, it consistent with that the previous researches, the mutants of these genes were observed with a dwarfing phenotype. The ZmGID1 and ZmGID2, F-box proteins modulate DELLA protein degradation, were both down-regulated in the elongation region of internode. And the $Z m C P S 3, Z m K S$ and $Z m K A O$, which were related to GA biosynthesis, were observed to be down-regulated in the elongation region of internode (Fig. 6a). In addition, the gibberellin stimulated-like proteins (ZmGSL1 and ZmCl22897_1a) 
were identified as being up-regulated by COR in the meristem region and elongating internode. Their homolog gene OsGASR3 was reported to reduce the toxicity of Xanthomonas campestris to rice and involvement in defense and affecting growth and development of rice [8]. While, we also found the DELLA protein ZmGras46 which is involved in controlling GA-induced growth and adaptability to environmental changes [44] was downregulated in the meristem region after COR treatment for 4 days. These results suggested that COR could control the expression of GA metabolic and biosynthesis genes and modulate the signal transduction for repressing internode elongation. Collectively, these regulated GA related genes might be essential for normal growth and defense processes, according to gene function annotation.

\section{Effect of COR on genes of JA pathway}

JAs are a small molecules compound derived from lipids that have core position in the transition between plant defense and normal growth. $80 \%$ of genes (28 genes) involved in JA were differentially expressed after COR treatment (Additional Data Sets 7). Unlike the gibberellin related genes which were significantly downregulated in the meristem region and elongation region, the JA related genes were most significantly upregulated in the fixed region (Fig. 6b). For example, in the oxylipin biosynthesis, the $Z m L O X s$, as defense signals, play important roles in inducing defense genes to work [14] most $Z m L O X s$ were up-regulated in the fixed region after COR treatment, included $Z m L O X 5$, ZmLOX6, ZmLOX9, ZmLOX10 and ZmLOX11. The ZmAOSs (Allene oxide synthase) which are responsible for production of JAs were up-regulated, such as $Z m A O S 1$ and ZmAOS2 were up-regulated in the fixed region and elongation region and $Z m A O S 3$ was mainly up-regulated in the fixed region. ZmOPR6 and ZmOPR8 encode enzymes with catalytic function that the adjacent double bond of $\alpha, \beta$-unsaturated aldehyde or ketone can be reduced were up-regulated in the all regions, it consistent with the previous report that ZmOPR6 and ZmOPR8 are highly promoted by wound-related

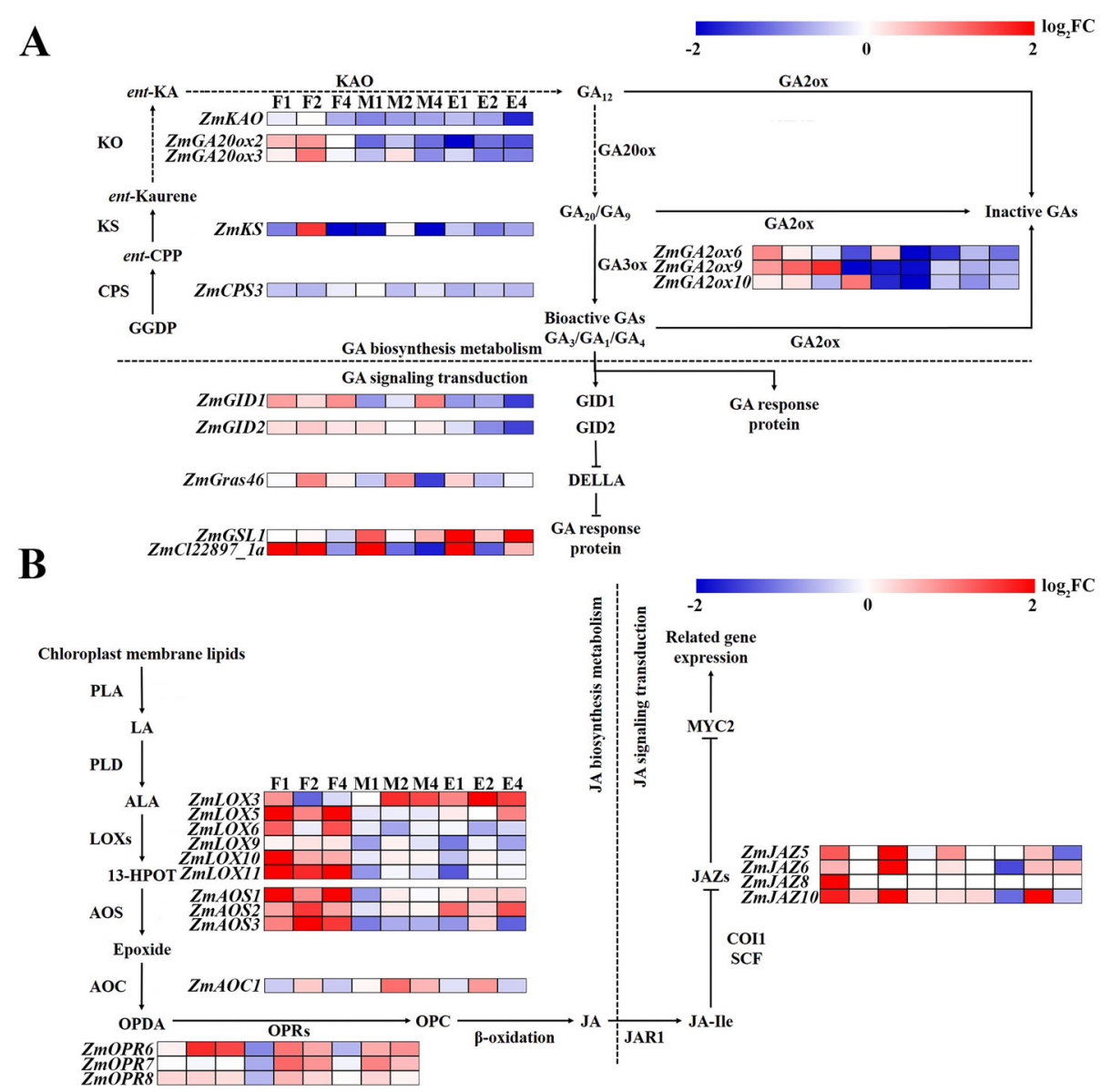

Fig. 6 The expression of genes in GA and JA pathways was affected by COR. $\mathbf{a}$ and $\mathbf{b}$ Effects of COR on GA (a) and JA (b) pathway genes. The degree of genes expression was indicated by $\log _{2}$ (foldchange). Red represents up-regulation and blue represents down-regulation. Colour bar indicates the degree of change. The enzymatic reaction pathway is shown with solid and dashed arrows 
signaling molecules, such as JA and ethylene [116]. And the $Z m O P R 7$ was up-regulated in the meristem region and elongation region. JAZ proteins as an inhibitory factor of JA signaling were also up-regulated in the fixed region, included ZmJAZ5 and ZmJAZ6 and ZmJAZ10 (Fig. 6b).

\section{Discussion}

COR can effectively reduce maize internode length, ear height and plant height

The prolonged cloudy and rainy days and other environmental factors always result in severe lodging of maize. Plant height is a crucial determinants of plant architecture in maize and is closely related to lodging resistance and canopy photosynthesis at high planting density. Moderately reducing plant height is an effective strategy for improving lodging resistance in maize grown at high density and bad environment. In this study, we confirmed that COR, as a new plant growth regulator, could effectively reduce plant height and ear height of both hybrids (ZD958 and XY335) and inbred (B73) maize by inhibiting internode growth during elongation and not cause yield per plant decline (Fig. 1). These results are a further verification and complement to previous research $[85,99]$.

\section{Dynamic changes of genes in different regions during internode development}

To understand its molecular mechanism of different internode region in response to COR treatment, we firstly analyzed the transcriptome data of the control group by 3 time points and constructed dynamic transcriptome landscape of developmental process of internode different regions (Fig. 3). The provided dynamic transcriptome data clearly demonstrated the three key regions of growing internode, including the fixed region, meristem region and elongation region, which the revealed occurrence regions are consistent with previously reported researches [117, 120, 121]. 2840, 5973 and 7462 genes were observed mainly expressing in the fixed region, meristem region, and elongation region, respectively, during the elongation growth of maize internode (Fig. 3). This gene bank provides a wealth of resources for future research, that will enhance our cognition of the genetic basis of internode development and also helps to understand the effect of COR on internode elongation. Especially, we detected 1376 stemcharacteristic genes (having $70 \mathrm{TFs}$ ), and they will become the focus in future research (Additional Fig. 5).

We found that the number of genes significantly regulated by $C O R$ in $M$ and $E$ regions is much higher than that in $\mathrm{F}$ region (Fig. 4). This showed that these two regions are most affected by COR, especially $\mathrm{E}$ region which is consistent with phenotypic results (Fig. 1d;
Additional Fig. 1B). The most genes affected by COR in the $\mathrm{E}$ region are related to transcription, translation and protein metabolism. We found that the genes of secondary wall and defense process were up-regulated, which has an inhibitory effect on plant height, such as ZmGRAS19, ZmDCL101 and ZmGST10 [21, 56, 89] (Fig. $5)$. In addition, the down-regulation of some cell wall synthesis-related genes, such as $\mathrm{ZmCesA10,ZmCesA12}$ and $Z m C e s A 13$, in the $\mathrm{E}$ region also inhibited cell elongation (Fig. 5).

\section{COR changed pathway of GA and JA during internode elongation}

GAs and JAs, two important plant hormones, have a vital role in controlling plant growth and development under the different environment. GA plays essential parts during plant developmental processes, and JA as a regulator controls the response to stress. In our study, we found the most gibberellin synthetic and responsive genes were significantly inhibited in the meristem region and elongation region, it consistent that reduced GA biosynthesis and suppression of GA signaling pathways lead to reduced plant height and internode shortening [3]. We also found JA related genes were most significantly up-regulated in the fixed region, it may be related to that the lignin most is produced and stored in the secondary cell walls of fixed region and the plant defense dominated by JAs is correlated with expression of genes of lignin synthesis [20,43]. These results suggested that COR treatment mainly controlled internode growth by activating the JA pathway in fixed region and inhibiting the GA pathway in the meristem region and elongation region, thereby reducing plant height (Fig. 7).

During the growth process of plants, the balance between defense and growth is a mutual conversion process, which is a necessary condition for plants to coordinate the supply of resources according to various growth clues and environmental challenges. Notably, in our study, we found some JAZ genes, which enable plants to shut down the JAs signaling pathway in time, were up-regulated, while DELLA protein ZmGras46, known as GA signal suppressor, was down-regulated in the meristem region after 4 days of COR treatment. So that the plant can timely from the defense state to the normal growth and development state. These results may explain why COR can effectively reduce plant height, but does not affect the subsequent maize plant growth and yield per plant.

\section{Conclusions}

In summary, our transcriptome data displays a map of gene expression during internode development and a difference of gene expression after COR treatment. The biosynthesis and signal transduction of GA in cells of 


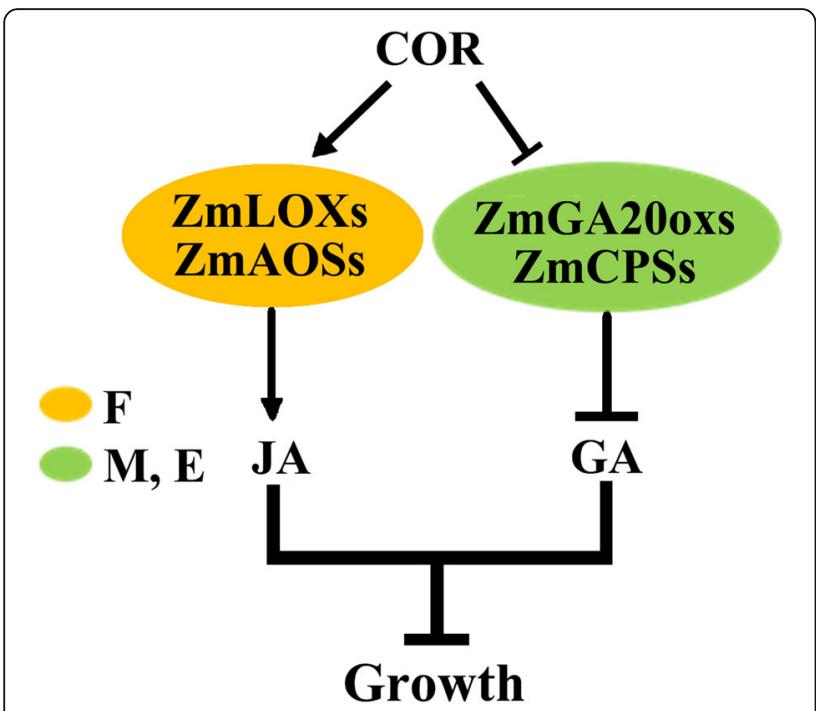

Fig. 7 Model graph of plant growth regulating by COR treatment. After treatment with COR, the JA pathway in fixed region is activated and GA pathway in the meristem region and elongation region is inhibited so that inhibit the growth of maize plant

internode elongation region are affected by COR. At the same time, genes related to cell wall and cytoskeleton in the cells of internode elongation region are also inhibited by COR, which affect the normal expansion of internode cells. This may be one of the reasons for the shortening of maize internodes and the decrease of maize plant height after treated by COR. It provides a solid foundation for future researches of the key factors involved in regulating internode length through COR and a theoretical basis for the application of COR.

\section{Methods}

\section{Plant materials}

The hybrids of maize ZD958 and XY335 were used in our experiment which were collected from the Henan Golddoctor Seeds Co., Ltd. and Shandong Denghai Pioneer Seeds Co., Ltd., respectively. The inbred of maize B73 was used in our experiment which were collected from the National Maize Improvement Center of China. The COR was purified by the Centre for Crop Chemical Control, College of Agriculture, China Agricultural University. The ZD958 and XY335 were cultivated in Jinan $\left(36^{\circ} 40^{\prime} \mathrm{N}, 117^{\circ} 00^{\prime} \mathrm{E}\right)$, Shandong Province, China, during the summer of 2018. The maize B73 was cultivated in the greenhouse characterized by $16 \mathrm{~h} / 8 \mathrm{~h}$ photoperiod, $25^{\circ} \mathrm{C} / 18^{\circ} \mathrm{C}$ day/night temperature.

\section{The COR treatment}

Coronatine was purified by the Centre for Crop Chemical Control, China Agricultural University. Coronatine purity was $>99 \%$, measured with high performance liquid chromatography (Milford, MA, USA). COR was dissolved in 10 folds $(\mathrm{m} / \mathrm{v})$ methanol and then diluted with water before foliar spraying. The time of treating with COR is the third day after the 9th leaf is fully deployed. The concentration of COR is $10 \mu \mathrm{mol} \cdot \mathrm{L}^{-1}$ and the total amount of liquid is $7 \mathrm{ml} \cdot$ plant $^{-1}[60,85,86]$. The maize treated with water, which was added the same amount of methanol as the experimental group, is control.

\section{Determination of phenotyping}

In the field experiments, we confirmed observation of the plant height, grain weight per plant and yield. We measured plant height by ruler in a separate experiment at late stage of filling, which included two treatments (COR or water) in a design of completely randomized. After harvesting, the yield and grain weight per plant are measured.

In the greenhouse, the length of 7th and 9th internode was measured at three time points (1st, 2nd, and 4th day after treatment, Fig. 2a). In addition, the length of 9th internode of B73 was measured by ruler and after measuring the height of plant and ear at late stage of filling. And the fracture resistance was tested by stem strength tester YYD-1 (Zhejiang TOP instrument Co., Ltd., Hangzhou, China). Finally, significance analysis of these data was conducted by $\mathrm{t}$ test using the software GraphPad Prism 8 [90].

\section{Microstructural observation of internode}

On the late stage of filling after COR treatment, the middle region of the 9th internode was collected from the stem of maize. The samples were processed in Carnoy's solution $(75 \%$ ethanol and $25 \%$ acetic acid mixed in equal volume) for $10 \mathrm{~h}$, and then saved in $70 \%$ ethanol. Cross sections were produced from the 9th internode by double-edge razor blades and then treated with safranin. The stem microstructure was observed using Olympus BX51 microscope (Olympus China Co., Ltd., Beijing, China) basing on the methods of Xu et al. [105].

\section{Experiment design}

Our experiment comprised two factors in the completely randomized factorial design. In this experiment two replicates were designed. The specific information of experiment as follows: (a) COR factor with two levels (control of water and treating with $10 \mu \mathrm{mol} \cdot \mathrm{L}^{-1} \mathrm{COR}$ ) and (b) region of sampling a segment of approximately $4 \mathrm{~mm}$ in the top $0-1 \mathrm{~cm}$ region of 7 th internode $(\mathrm{F})$, a segment of approximately $4 \mathrm{~mm}$ in the base $0-1 \mathrm{~cm}$ region of 9th internode $(\mathrm{M})$ and a segment of approximately $4 \mathrm{~mm}$ in the base $1-2 \mathrm{~cm}$ region of 9 th internode (E) with three time points (1st, 2nd and 4th day after treating with $10 \mu \mathrm{mol} \cdot \mathrm{L}^{-1}$ COR) [119] (Additional Fig. 2).Thirty-six samples were taken for RNA extraction. Each sample 
was collected form at least three plants with the scalpel, collected in a $50 \mathrm{ml}$ tube, immediately placed in liquid nitrogen, and finally stored in an ultra-low temperature refrigerator $\left(-80^{\circ} \mathrm{C}\right)$. Each time a sample was taken, the scalpel was rinsed with Milli Q water.

\section{RNA extraction and preparing library}

Total RNA from all the samples was extracted using the Trizol (produced by Invitrogen) basing on the manual. Then the total RNA was purified by magnetic stand (Invitrogen). The Aliquots of total RNA purified were stored in the $-80^{\circ} \mathrm{C}$ refrigerator. The libraries of sequencing were constructed by $5 \mu \mathrm{g}$ total RNA using the TruSeq $^{\mathrm{Tm}}$ RNA sample preparation Kit (Illumina Inc., San Diego, USA) following the instructions of manufacturer. According to the protocol of library construction (Illumina), synthetic cDNA was treated with end-repair, phosphorylation and 'A' base addition. After PCR treated by NEB's Phusion DNA polymerase for 15 cycles, selection of size was performed for target fragments of cDNA on 2\% Agarose of Low Range Ultra (Bio-Rad). The size of cDNA target fragments is $200-300 \mathrm{bp}$. Then the libraries were quantitated with TBS380 Picogreen (Invitrogen). All libraries of paired-end sequencing were sequenced using the HiSeq xten $(2 \times 150 \mathrm{bp}$ read length) (Illumina Inc., San Diego, USA).

\section{RNA-seq data analysis}

In order to align the reads of paired-end and control the quality of reads, we trimmed the paired-end reads and filtered the illumina reads with the SeqPrep (https:// github.com/jstjohn/SeqPrep) and Sickle (https://github. com/najoshi/sickle), respectively. Then, the mapping of reads to the reference genome of maize (from the MaizeGDB) is performed using the Hisat2 [53]. The unique mapped reads were processed using the Cufflinks (V2.2.0) software [33]. PFKM was used to indicate the gene expression level. The $R^{2}$ between biological replicates was calculated. And correlation pictures were made through the prcomp function of $\mathrm{R}$ software [87] with initial settings to be convenient for graphic description of correlation among all samples with $\log _{2}$ (FPKM+ 1).

The prcomp function in R software was used for PCA analysis [87] with original parameters to be easy to graphic display of relatedness among all samples. The $\log _{2}($ FPKM +1$)$ of the genes were used for the analysis of PCA by R (V 3.6.1).

\section{Gene coexpression analysis}

Using the k-means algorithm of $\mathrm{MeV}$ (V4.9) software for the co-expression analysis for 9 different no-treatment samples [87]. The normalized expression of genes was operated by dividing their expression level at all samples with their maximum FPKM. The optimal cluster number was determined by the Figure of merit [113].

\section{Differential expression analysis}

In order to discover COR-RGs between two different samples, following the method of FPKM, each transcript's expression level of was calculated. Then the differentially expressed genes were calculated by using Cuffdiff, a part of the Cufflinks package (http://cufflinks. cbcb.umd.edu/) [91].

\section{Functional enrichment analysis}

Then using the function annotation module in MapMan (v3.6.0) [88] for evaluating functional category enrichment with each co-expression module. After choosing the representative protein (which was the longest protein of each gene) and running the Mercator with default settings, we conducted the MapMan annotation. Whether there are too many functional categories for a given module was tested by Fisher's exact test. The Benjamini-Hochberg correction was used to result $p$-values were adjusted to $\mathrm{Q}$ values, and $5 \%$ fault tolerance rate was applied.

\section{Screening expression of stem-specific gene}

For screening of stem-specific genes, 18 stem samples collected from our study and 19 non-stem transcriptome data $[18,23,59,63,96]$ collected from the NCBI (http:// www.ncbi.nlm.nih.gov/) were used. We used an already reported method [11, 114]. Firstly, the normalization of the expression values of all samples was performed with $\log _{2}$ (FPKM+ 0.01). Secondly, the z-scores of the genes collected in different stem tissues compared with the nonstem tissues using the normalized expression value was performed. If one gene had a $\mathrm{z}$-score greater than 3 in at least one of the samples of stem, this gene was determined to be stem specifically expressed. Then, combining the differentially expressed genes from the transcriptome data that we generated, we further explored the effects of COR for genes expression by performing co-expression analysis using the MeV (V4.9) software.

\section{Abbreviations \\ COR: Coronatine; JA: Jasmonate; COR-RGs: COR-responsive gene; GA: Gibberellin; DPC: 1,1-dimethyl-piperidinium chloride; FPKM: Fragments per kilobase of transcript per million mapped reads; TF: Transcription factor; PCA: Principal component analysis; F: Fixed region; M: Meristem region; E: Elongation region; FDR: False discovery rate; EREBP: Ethylene-responsive element binding protein}

\section{Supplementary Information}

The online version contains supplementary material available at https://doi. org/10.1186/s12870-021-02962-2.

Additional file 1: Fig. S1 The effects of COR for ZD958, XY335 and the internode of B73. (A) Gross morphologies of ZD958 and XY335 with and 
without COR treatment. Scale bars, $30 \mathrm{~cm}$. (B) Gross morphologies of 7th and 9th internode with and without COR treatment at three points after COR treatment. Scale bars, $1 \mathrm{~cm}$.

Additional file 2: Fig. S2 The effects of COR for maize yield and microstructure of the 9th internode. (A) The yield of two maize hybrids was significantly increased by COR treatment. The data were presented as means \pm SE $(n=4)$. SE is represented by error bars. ${ }^{* *}$ : $p$-value $<0.001$ (B) Microstructure of the cross section of the 9th internode. The bar is $500 \mu \mathrm{m}$

Additional file 3: Fig. S3 Correlation between biological replicates of samples for RNA-seq. The calculation of the correlation coefficient is carried out using normalized values of $\log _{2}$ (FPKM value +1 ).

Additional file 4: Fig. S4 The gene differential expression modules and functional enrichment analysis. (A) The genes, which were differential expressed in more than one region by $\mathrm{COR}$, were display in here. The FPKM values of each gene were divided by the maximum value in all CK samples for normalization. (B) Function classification enrichment of genes in different modules is performed using MapMan. Only items of FDR less than 0.05 are displayed.

Additional file 5: Fig. S5 Expression maps of internode-specific genes. Expression maps of stem-specific genes in each region. The FPKM values of each gene were divided by the maximum value in all CK samples for normalization

Additional file 6: Fig. $\mathbf{S 6}$ The differential expression module and functional enrichment analysis of COR-RGs in the stem-specific expression gene. (A) Differential expression modules of stem-specific genes in different internode regions after COR treatment. The FPKM values of each gene were divided by the maximum value in all CK samples for normalization. (B) Function classification enrichment of genes in different modules is performed using MapMan. Only items of FDR less than 0.05 are displayed.

Additional file 7: Fig. $\mathbf{S 7}$ Effect of COR on Genes in GA, JA, IAA and ABA.

Additional file 8: Table S1. Statistics of reads in all samples.

Additional file 9: Table S2. The number of JA, GA, ABA and IAA genes affected by COR.

Additional file 10: Table S3. GenBank ID of all genes mentioned in this study.

Additional file 11: Data Sets 1. Determination of phenotyping.

Additional file 12: Data Sets 2 . Expression pattern of genes and TFs in all samples.

Additional file 13: Data Sets 3. Expression pattern of genes and TFs in control samples.

Additional file 14: Data Sets 4. DEGs and TFs of DEGs in this study. Additional file 15: Data Sets 5. Information of stem-specific expressed genes in this study.

Additional file 16: Data Sets 6. Information of DEGs in stem-specific expression genes.

Additional file 17: Data Sets 7. Information of DEGs in the GA and JA pathway

\section{Acknowledgements}

Not applicable.

\section{Authors' contributions}

Y.Y.Z. and L.S.D. designed the research; Z.B.R., X.W., G.M.H. and Y.X.L. performed the maize stem morphology observation; Z.B.R., F.Y., Q.G. and Q.T. analyzed the data; M.C.Z. and Z.H.L. provided some constructive suggestions; Z.B.R., F.Y., X.W. and L.S.D. wrote and revised the paper. All authors reviewed the manuscript.

\section{Funding}

This work, including the design of the study, the data collection, analysis and interpretation and write manuscript, was supported by the National Science Fund for Distinguished Young Scholars (31425017) and the National Key
Research and Development Program of China (2017YFD0201300). The funders had no other role during the experiment and preparation of the manuscript.

\section{Availability of data and materials}

The gene sequence information mentioned in this study could be found from the literature based on the gene list in Additional Table 2.

Transcriptome information from this research can be downloaded in the NCBI Sequence Read Archive (http://www.ncbi.nlm.nih.gov/sra through accession number PRJNA633707. Other data produced during this study are included in our article and in its supplementary files.

\section{Declarations}

Ethics approval and consent to participate

Not applicable.

\section{Consent for publication}

Not applicable.

\section{Competing interests}

The authors declare that they have no competing interests.

\section{Author details}

${ }^{1}$ State Key Laboratory of Plant Physiology and Biochemistry, Engineering Research Center of Plant Growth Regulator, Ministry of Education \&College of Agronomy and Biotechnology, China Agricultural University, No.2 Yuanmingyuan West Road, Haidian, Beijing 100193, China. ${ }^{2}$ College of Plant Science and Technology, Beijing University of Agriculture, No.7 Beinong Road, Changping, Beijing 102206, China.

Received: 4 September 2020 Accepted: 7 April 2021

Published online: 27 April 2021

\section{References}

1. Ambasht P, Kayastha AM. Plant pyruvate kinase. Biol Plant. 2002;45(1):1-10. https://doi.org/10.1023/A:1015173724712.

2. Appenzeller L, Doblin M, Barreiro R, Wang H, Niu X, Kollipara K, et al. Cellulose synthesis in maize: isolation and expression analysis of the cellulose synthase (CesA) gene family. Cellulose. 2004;11(3/4):287-99. https://doi.org/10.1023/B:CELL.0000046417.84715.27.

3. Ayano M, Kani T, Kojima M, Sakakibara H, Kitaoka T, Kuroha T, et al. Gibberellin biosynthesis and signal transduction is essential for internode elongation in Deepwater rice. Plant Cell Environ. 2014;37(10):2313-24. https://doi.org/10.1111/pce.12377.

4. Ballif J, Endo S, Kotani M, MacAdam J, Wu Y. Over-expression of HAP3b enhances primary root elongation in Arabidopsis. Plant Physiol Biochem. 2011:49(6):579-83. https://doi.org/10.1016/j.plaphy.2011.01.013.

5. Bashline L, Du J, Gu Y. The trafficking and behavior of cellulose synthase and a glimpse of potential cellulose synthesis regulators. Front Biol. 2011 ; 6(5):377-83. https://doi.org/10.1007/s11515-011-1161-3.

6. Belt K, Huang S, Thatcher LF, Casarotto H, Singh KB, Van Aken O, et al. Salicylic acid-dependent plant stress signaling via mitochondrial succinate dehydrogenase. Plant Physiol. 2017;173(4):2029-40. https://doi.org/10.1104/ pp.16.00060.

7. Bensen RJ, Johal GS, Crane VC, Tossberg JT, Schnable PS, Meeley RB, et al. Cloning and characterization of the maize An1 gene. Plant Cell. 1995;7(1): 75-84. https://doi.org/10.1105/tpc.7.1.75

8. Boonpa $\mathrm{K}$, Tantong $\mathrm{S}$, Weerawanich $\mathrm{K}$, Panpetch $\mathrm{P}$, Pringsulaka $\mathrm{O}$, Yingchutrakul Y, et al. Heterologous expression and antimicrobial activity of OsGASR3 from rice (Oryza sativa L.). J. Plant Physiol. 2018;224:95-102.

9. Brown D, Wightman R, Zhang Z, Gomez LD, Atanassov I, Bukowski JP, et al. Arabidopsis genes IRREGULAR XYLEM (IRX15) and IRX15L encode DUF579containing proteins that are essential for normal xylan deposition in the secondary cell wall. Plant J. 2011;66(3):401-13. https://doi.org/10.1111/j.13 65-313X.2011.04501x

10. Castano-Duque L, Luthe DS. Protein networks reveal organ-specific defense strategies in maize in response to an aboveground herbivore. ArthropodPlant Inte. 2018;12(1):147-75. https://doi.org/10.1007/s11829-017-9562-0. 
11. Chen J, Zeng B, Zhang M, Xie S, Wang G, Hauck A, et al. Dynamic transcriptome landscape of maize embryo and endosperm development. Plant Physiol. 2014a;166(1):252-64. https://doi.org/10.1104/pp.114.240689.

12. Chen $Y$, Hou M, Liu L, Wu S, Shen $Y$, Ishiyama $K$, et al. The maize DWARF1 encodes a gibberellin 3-oxidase and is dual localized to the nucleus and cytosol. Plant Physiol. 2014b;166(4):2028-39. https://doi.org/10.1104/ pp.114.247486.

13. Christensen SA, Huffaker A, Kaplan F, Sims J, Ziemann S, Doehlemann G, et al. Maize death acids, 9-lipoxygenase-derived cyclopente (a) nones, display activity as cytotoxic phytoalexins and transcriptional mediators. Proc Natl Acad Sci U S A. 2015;112(36):11407-12. https://doi.org/10.1073/pnas.1 511131112.

14. Christensen SA, Nemchenko A, Borrego E, Murray I, Sobhy IS, Bosak L, et al. The maize lipoxygenase, Zm LOX 10, mediates green leaf volatile, jasmonate and herbivore-induced plant volatile production for defense against insect attack. Plant J. 2013;74(1):59-73. https://doi.org/10.1111/ tpj.12101.

15. Cosgrove DC. Comparative structure and biomechanics of plant primary and secondary cell walls. Front Plant Sci. 2012;3:204.

16. Cui K, He CY, Zhang JG, Duan AG, Zeng YF. Temporal and spatial profiling of internode elongation-associated protein expression in rapidly growing culms of bamboo. J Proteome Res. 2012;11(4):2492-507. https://doi.org/10.1 021/pr2011878.

17. Datta R, Chourey P. Sugar-regulated control of a-tubulin in maize cell suspension culture. Plant Cell Rep. 2001;20(3):262-6. https://doi.org/10.1007/ s002990000310

18. Davidson RM, Hansey CN, Gowda M, Childs KL, Lin H, Vaillancourt B, et al. Utility of RNA sequencing for analysis of maize reproductive transcriptomes. Plant Genome. 2011;4(3):191-203. https://doi.org/10.3835/plantgenome2011. 05.0015 .

19. Deleris A, Gallego-Bartolome J, Bao J, Kasschau KD, Carrington JC, Voinnet O. Hierarchical action and inhibition of plant dicer-like proteins in antiviral defense. Science. 2006;313(5783):68-71. https://doi.org/10.1126/science.112 8214.

20. Denness L, McKenna JF, Segonzac C, Wormit A, Madhou P, Bennett M, et al. Cell wall damage-induced lignin biosynthesis is regulated by a reactive oxygen species-and jasmonic acid-dependent process in Arabidopsis. Plant Physiol. 2011;156(3):1364-74. https://doi.org/10.1104/pp.111.175737.

21. Dixon DP, Lapthorn A, Edwards R. Plant glutathione transferases. Genome biol. 2002;3:reviews3004.1.

22. Douglas CJ. Phenylpropanoid metabolism and lignin biosynthesis: from weeds to trees. Trends Plant Sci. 1996;1(6):171-8. https://doi.org/10.1016/13 60-1385(96)10019-4.

23. Downs GS, Bi Y-M, Colasanti J, Wu W, Chen X, Zhu T, et al. A developmental transcriptional network for maize defines coexpression modules. Plant Physiol. 2013;161(4):1830-43. https://doi.org/10.1104/pp.112.213231.

24. Fagard M, Desnos T, Desprez T, Goubet F, Refregier G, Mouille G, et al. PROCUSTE1 encodes a cellulose synthase required for normal cell elongation specifically in roots and dark-grown hypocotyls of Arabidopsis. Plant Cell. 2000;12(12):2409-23. https://doi.org/10.1105/ tpc.12.12.2409.

25. Faik A, Price NJ, Raikhel NV, Keegstra K. An Arabidopsis gene encoding an a-xylosyltransferase involved in xyloglucan biosynthesis. Proc Natl Acad Sci U S A. 2002;99(11):7797-802. https://doi.org/10.1073/pnas.102644799.

26. Farag MA, Fokar M, Abd H, Zhang H, Allen RD, Pare PW. (Z)-3-Hexenol induces defense genes and downstream metabolites in maize. Planta. 2005; 220(6):900-9. https://doi.org/10.1007/s00425-004-1404-5.

27. Fernández-Pérez F, Pomar F, Pedreño MA, Novo-Uzal E. Suppression of Arabidopsis peroxidase 72 alters cell wall and phenylpropanoid metabolism. Plant Sci. 2015;239:192-9. https://doi.org/10.1016/j.plantsci.2015.08.001.

28. Fu Y, Li H, Yang Z. The ROP2 GTPase controls the formation of cortical fine F-actin and the early phase of directional cell expansion during Arabidopsis organogenesis. Plant Cell. 2002;14(4):777-94. https://doi. org/10.1105/tpc.001537.

29. Gómez LD, Baud S, Gilday A, Li Y, Graham IA. Delayed embryo development in the ARABIDOPSIS TREHALOSE-6-PHOSPHATE SYNTHASE 1 mutant is associated with altered cell wall structure, decreased cell division and starch accumulation. Plant J. 2006:46(1):69-84. https://doi.org/10.1111/j.1365-313X.2 006.02662.x

30. Gao X, Starr J, Gobel C, Engelberth J, Feussner I, Tumlinson J, et al. Maize 9lipoxygenase ZmLOX3 controls development, root-specific expression of defense genes, and resistance to root-knot nematodes. Mol Plant-Microbe interact. 2008;21(1):98-109. https://doi.org/10.1094/MPMI-21-1-0098.

31. Garza-Aguilar SM, Axosco-Marín J, Lara-Núñez A, Guerrero-Molina ED, Lemus-Enciso AT, García-Ramírez E, et al. Proliferating cell nuclear antigen associates to protein complexes containing cyclins/cyclin dependent kinases susceptible of inhibition by KRPs during maize germination. Plant Sci. 2019;280:297-304. https://doi.org/10.1016/j.plantsci.2018.12.020.

32. Geisler M, Murphy AS. The ABC of auxin transport: the role of $\mathrm{p}$ glycoproteins in plant development. FEBS Lett. 2006;580(4):1094-102. https://doi.org/10.1016/j.febslet.2005.11.054.

33. Ghosh S, Chan C-KK. Analysis of RNA-Seq data using TopHat and cufflinks. Plant Bioinformatics. 2016:339-61. https://doi.org/10.1007/978-1-4939-3167-5_18.

34. Gorman Z, Christensen SA, Yan Y, He Y, Borrego E, Kolomiets MV. Green leaf volatiles and jasmonic acid enhance susceptibility to anthracnose diseases caused by Colletotrichum graminicola in maize. Mol Plant Pathol. 2020;21(5): 702-15. https://doi.org/10.1111/mpp.12924.

35. Gray WM. Hormonal regulation of plant growth and development. PLoS Biol. 2004;2(9):E311. https://doi.org/10.1371/journal.pbio.0020311.

36. Gruelich F, Yoshihara T, Ichihara A. Coronatine, a bacterial phytotoxin, acts as a stereospecific analog of jasmonate type signals in tomato cells and potato tissue. Plant Physiol. 1995:147(3-4):359-66. https://doi.org/10.1016/ S0176-1617(11)82168-1.

37. Guillet-Claude C, Birolleau-Touchard C, Manicacci D, Rogowsky PM, Rigau J, Murigneux A, et al. Nucleotide diversity of the ZmPox3 maize peroxidase gene: relationships between a MITE insertion in exon 2 and variation in forage maize digestibility. BMC Genet. 2004;5(1):19. https://doi.org/10.11 86/1471-2156-5-19.

38. Guo $X$, Hou X, Fang J, Wei $P$, Xu B, Chen $M$, et al. The rice GERMINATION DEFECTIVE 1, encoding a B3 domain transcriptional repressor, regulates seed germination and seedling development by integrating GA and carbohydrate metabolism. Plant J. 2013;75(3):403-16. https://doi.org/1 $0.1111 /$ tpj.12209.

39. Hamant O, Traas J. The mechanics behind plant development. New Phytol. 2010;185(2):369-85. https://doi.org/10.1111/j.1469-8137.2009.03100.x.

40. Hao L, Wang Y, Zhang J, Xie Y, Zhang M, Duan L, et al. Coronatine enhances drought tolerance via improving antioxidative capacity to maintaining higher photosynthetic performance in soybean. Plant Sci. 2013; 210:1-9. https://doi.org/10.1016/j.plantsci.2013.05.006.

41. Hemerly A, Bergounioux C, Van Montagu M, Inze D, Ferreira P. Genes regulating the plant cell cycle: isolation of a mitotic-like cyclin from Arabidopsis thaliana. Pro Natl Acad Sci USA. 1992;89(8):3295-9. https://doi. org/10.1073/pnas.89.8.3295.

42. Hernández-Altamirano JM, Largo-Gosens A, Martínez-Rubio R, Pereda D, Álvarez JM, Acebes JL, et al. Effect of ancymidol on cell wall metabolism in growing maize cells. Planta. 2018;247(4):987-99. https://doi.org/10.1007/ s00425-018-2840-y.

43. Hu Q, Min L, Yang X, Jin S, Zhang L, Li Y, et al. Laccase GhLac1 modulates broad-spectrum biotic stress tolerance via manipulating phenylpropanoid pathway and jasmonic acid synthesis. Plant Physiol. 2018;176(2):1808-23. https://doi.org/10.1104/pp.17.01628.

44. Hu S, Wang C, Sanchez DL, Lipka AE, Liu P, Yin Y, et al. Gibberellins promote brassinosteroids action and both increase heterosis for plant height in maize (Zea mays L.). front. Plant Sci. 2017;8:1039.

45. Huang X, Hou L, Meng J, You H, Li Z, Gong Z, et al. The antagonistic action of abscisic acid and cytokinin signaling mediates drought stress response in Arabidopsis. Mol Plant. 2018;11(7):970-82. https://doi.org/10.1016/j.molp.2018.05.001.

46. Ichihara A, Shiraishi K, Sato H, Sakamura S, Nishiyama K, Sakai R, et al. The structure of coronatine. J Am Chem Soc. 1977;99(2):636-7. https://doi.org/1 0.1021/ja00444a067.

47. Irvine RF, Schell MJ. Back in the water: the return of the inositol phosphates. Nat Rev Mol Cell Biol. 2001;2(5):327-38. https://doi.org/10.1038/35073015.

48. Jiao Y, Peluso P, Shi J, Liang T, Stitzer MC, Wang B, et al. Improved maize reference genome with single-molecule technologies. Nature. 2017; 546(7659):524-7. https://doi.org/10.1038/nature22971.

49. Jolie RP, Duvetter T, Van Loey AM, \& Hendrickx ME. Pectin methylesterase and its proteinaceous inhibitor: a review. Carbohydrate Research, 2010; 345(18):2583-95. https://doi.org/10.1016/j.carres.2010.10.002.

50. Katsir L, Schilmiller AL, Staswick PE, He SY, Howe GA. COl1 is a critical component of a receptor for jasmonate and the bacterial virulence factor coronatine. Proc Natl Acad Sci U S A. 2008;105(19):7100-5. https://doi.org/1 0.1073/pnas.0802332105. 
51. Kende H, Van Der Knaap E, Cho H-T. Deepwater rice: a model plant to study stem elongation. Plant Physiol. 1998;118(4):1105-10. https://doi.org/10.1104/ pp.118.4.1105

52. Khosravi GR, Anderson I. Growth, yield, and yield components of ethephontreated corn. Plant Growth Regul. 1991;10(1):27-36. https://doi.org/10.1007/ BF00035128.

53. Kim D, Paggi JM, Park C, Bennett C, Salzberg SL. Graph-based genome alignment and genotyping with HISAT2 and HISAT-genotype. Nat Biotechnol. 2019;37(8):907-15. https://doi.org/10.1038/s41587-019-0201-4.

54. Knoller AS, Blakeslee JJ, Richards EL, Peer WA, Murphy AS. Brachytic2/ ZmABCB1 functions in IAA export from intercalary meristems. J Exp Bot. 2010;61(13):3689-96. https://doi.org/10.1093/jxb/erq180.

55. Komorisono M, Ueguchi-Tanaka M, Aichi I, Hasegawa Y, Ashikari M, Kitano $\mathrm{H}$, et al. Analysis of the rice mutant dwarf and gladius leaf 1 Aberrant katanin-mediated microtubule organization causes up-regulation of gibberellin biosynthetic genes independently of gibberellin signaling. Plant Physiol. 2005;138(4):1982-93. https://doi.org/10.1104/pp.105.062968.

56. Kumar D, Kellogg EA. Getting closer: vein density in C4 leaves. New Phytol. 2019;221(3):1260-7. https://doi.org/10.1111/nph.15491.

57. Lee $\mathrm{Y}, \mathrm{Kende} \mathrm{H}$. Expression of $\beta$-expansins is correlated with internodal elongation in Deepwater rice. Plant Physiol. 2001;127(2):645-54. https://doi. org/10.1104/pp.010345.

58. Li J, Harper LC, Golubovskaya I, Wang CR, Weber D, Meeley RB, et al. Functional analysis of maize RAD51 in meiosis and double-strand break repair. Genetics. 2007;176(3):1469-82. https://doi.org/10.1534/genetics.106.062604.

59. Li P, Ponnala L, Gandotra N, Wang L, Si Y, Tausta SL, et al. The developmental dynamics of the maize leaf transcriptome. Nat Genet. 2010; 42(12):1060-7. https://doi.org/10.1038/ng.703.

60. Li Y, Huang G, Guo Y, Zhou Y, Duan L. Coronatine enhances stalk bending resistance of maize, thickens the Cell Wall and decreases the area of the vascular bundles. Agronomy. 2020;10(6):807. https://doi.org/10.3390/a gronomy10060807.

61. Liu Y, Poulin C, Filiatrault M. Expression patterns of plant defense genes during early stem infection of susceptible and tolerant potatoes by Dickeya dadantii. International congress of plant pathology abstracts and proceedings 1167-P; 2018.

62. Liu Y, Zhou Y, Huang G, Zhu N, Li Z, Zhang M, et al. Coronatine inhibits mesocotyl elongation by promoting ethylene production in etiolated maize seedlings. Plant Growth Regul. 2020;90(1):51-61. https://doi.org/10.1007/s1 0725-019-00555-6.

63. Ma J, Duncan D, Morrow DJ, Fernandes J, Walbot V. Transcriptome profiling of maize anthers using genetic ablation to analyze pre-meiotic and tapetal cell types. Plant J. 2007;50(4):637-48. https://doi.org/10.1111/j.1365-313X.2 007.03074.x.

64. Multani DS, Briggs SP, Chamberlin MA, Blakeslee JJ, Murphy AS, Johal GS. Loss of an MDR transporter in compact stalks of maize br2 and sorghum dw3 mutants. Science. 2003;302(5642):81-4. https://doi.org/10.1126/ science.1086072.

65. Nelissen H, Eeckhout D, Demuynck K, Persiau G, Walton A, Van Bel M, et al. Dynamic changes in ANGUSTIFOLIA3 complex composition reveal a growth regulatory mechanism in the maize leaf. Plant Cell. 2015;27(6):1605-19. https://doi.org/10.1105/tpc.15.00269.

66. Norberg O, Mason S, Lowry S. Ethephon influence on harvestable yield, grain quality, and lodging of corn. Agron J. 1988;80(5):768-72. https://doi. org/10.2134/agronj1988.00021962008000050015x.

67. Okushima Y, Overvoorde PJ, Arima K, Alonso JM, Chan A, Chang C, et al. Functional genomic analysis of the AUXIN RESPONSE FACTOR gene family members in Arabidopsis thaliana: unique and overlapping functions of ARF7 and ARF19. Plant Cell. 2005;17(2):444-63. https://doi.org/10.1105/tpc.104.028316.

68. Peng C, Wang X, Feng T, He R, Zhang M, Li Z, et al. System analysis of MIRN As in maize internode elongation. Biomolecules. 2019;9(9):417. https://doi. org/10.3390/biom9090417.

69. Peng X, Zhao Y, Li X, Wu M, Chai W, Sheng L, et al. Genomewide identification, classification and analysis of NAC type gene family in maize. J Genet. 2015;94(3):377-90. https://doi.org/10.1007/s12041-015-0526-9.

70. Rademacher W. Growth retardants: effects on gibberellin biosynthesis and other metabolic pathways. Annu Rev Plant Biol. 2000;51(1):501-31. https:// doi.org/10.1146/annurev.arplant.51.1.501.

71. Rademacher W. Chemical regulators of gibberellin status and their application in plant production. Annu Plant Rev Online. 2018:359-403. https://doi.org/10.1002/9781119312994.apr0541.
72. Ronceret A, Golubovskaya I, Ku J-C, Lee DH, Timofejeva L, Angoa AKG, et al. Dynamic localization of SPO11-1 and conformational changes of meiotic axial elements during recombination initiation of maize meiosis. PLoS Genetics, 16(4):e1007881. https://doi.org/10.1371/journal.pgen.1007881.

73. Sakamoto T, Miura K, Itoh H, Tatsumi T, Ueguchi-Tanaka M, Ishiyama K, et al. An overview of gibberellin metabolism enzyme genes and their related mutants in rice. Plant Physiol. 2004;134(4):1642-53. https://doi.org/10.1104/ pp.103.033696.

74. Salesse-Smith CE, Sharwood RE, Busch FA, Kromdijk J, Bardal V, Stern DB. Overexpression of Rubisco subunits with RAF1 increases Rubisco content in maize. Nat Plants. 2018;4(10):802-10. https://doi.org/10.1038/ s41477-018-0252-4.

75. Santner A, Calderon-Villalobos LIA, Estelle M. Plant hormones are versatile chemical regulators of plant growth. Nat Chem Biol. 2009;5(5):301-7. https://doi.org/10.1038/nchembio.165.

76. Santner A, Estelle M. Recent advances and emerging trends in plant hormone signalling. Nature. 2009;459(7250):1071-8. https://doi.org/10.1038/ nature08122.

77. Schnittger A, Weinl C, Bouyer D, Schöbinger U, Hülskamp M. Misexpression of the cyclin-dependent kinase inhibitor ICK1/KRP1 in single-celled Arabidopsis trichomes reduces endoreduplication and cell size and induces cell death. Plant Cell. 2003;15(2):303-15. https://doi.org/10.1105/tpc.008342.

78. Sharma N, Bender $Y$, Boyle K, Fobert PR. High-level expression of sugar inducible gene2 (HS/2) is a negative regulator of drought stress tolerance in Arabidopsis. BMC Plant Biol. 2013;13(1):170. https://doi.org/10.1186/1471-222 9-13-170.

79. Shikata M, Matsuda Y, Ando K, Nishii A, Takemura M, Yokota A, et al. Characterization of Arabidopsis ZIM, a member of a novel plant-specific GATA factor gene family. J Exp Bot. 2004;55(397):631-9. https://doi.org/10.1 093/jxb/erh078.

80. Solomon M, Belenghi B, Delledonne M, Menachem E, Levine A. The involvement of cysteine proteases and protease inhibitor genes in the regulation of programmed cell death in plants. Plant Cell. 1999;11(3):431-43. https://doi.org/10.1105/tpc.11.3.431.

81. Spray CR, Kobayashi M, Suzuki Y, Phinney BO, Gaskin P, MacMillan J. The dwarf-1 (dt) mutant of Zea mays blocks three steps in the gibberellinbiosynthetic pathway. Proc Natl Acad Sci U S A. 1996;93(19):10515-8. https://doi.org/10.1073/pnas.93.19.10515.

82. Starr JL, Yang W, Yan Y, Crutcher F, Kolomiets M. Expression of phenylalanine ammonia lyase genes in maize lines differing in susceptibility to meloidogyne incognita. J Nematol. 2014;46(4):360-4.

83. Stavang JA, Lindgard B, Erntsen A, Lid SE, Moe R, Olsen JE. Thermoperiodic stem elongation involves transcriptional regulation of gibberellin deactivation in pea. Plant Physiol. 2005;138(4):2344-53. https://doi.org/10.11 04/pp.105.063149.

84. Sun L, Zhu L, Xu L, Yuan D, Min L, Zhang X. Cotton cytochrome P450 CYP82D regulates systemic cell death by modulating the octadecanoid pathway. Nat Commun. 2014:5:1-12.

85. Tao Q, Huang G, Guo Q, Zhou Y, Tan W, Zhang M, et al. Effects of coronatine on lodging resistance and yield of maize. Chin J Pesticide Sci. 2019a;21:43-51 (in chinese. https://doi.org/10.16801/j.issn.1008-7303.2019.0006.

86. Tao Q, Liu Y, Guo Y, Zhou Y, Tan W, Zhang M, et al. Study of coronatine in regulating the basal internode and root characteristics of maize. J China Agric Univ. 2019b;24:1-9 (in chinese. https://doi.org/10.11841/j.issn.1 007-4333.2019.03.01

87. Team RC. R: a language and environment for statistical computing; 2013.

88. Thimm O, Bläsing $O$, Gibon $Y$, Nagel A, Meyer S, Krüger $P$, et al. MAPMAN: a user-driven tool to display genomics data sets onto diagrams of metabolic pathways and other biological processes. Plant J. 2004;37(6):914-39. https:// doi.org/10.1111/j.1365-313X.2004.02016.X.

89. Thompson BE, Basham C, Hammond R, Ding Q, Kakrana A, Lee T-F, et al. The dicer-like1 homolog fuzzy tassel is required for the regulation of meristem determinacy in the inflorescence and vegetative growth in maize. Plant Cell. 2014;26(12):4702-17. https://doi.org/10.1105/tpc.114.132670.

90. Tian J, Wang C, Xia J, Wu L, Xu G, Wu W, et al. Teosinte ligule allele narrows plant architecture and enhances high-density maize yields. Science. 2019; 365(6454):658-64. https://doi.org/10.1126/science.aax5482.

91. Trapnell C, Roberts A, Goff L, Pertea G, Kim D, Kelley DR, et al. Differential gene and transcript expression analysis of RNA-seq experiments with TopHat and cufflinks. Nat Protoc. 2012;7(3):562-78. https://doi.org/10.1038/ nprot.2012.016. 
92. Tunc-Ozdemir M, Miller G, Song L, Kim J, Sodek A, Koussevitzky S, et al. Thiamin confers enhanced tolerance to oxidative stress in Arabidopsis. Plant Physiol. 2009;151(1):421-32. https://doi.org/10.1104/pp.109.140046.

93. Uppalapati SR, Ayoubi P, Weng H, Palmer DA, Mitchell RE, Jones W, et al. The phytotoxin coronatine and methyl jasmonate impact multiple phytohormone pathways in tomato. Plant J. 2005;42(2):201-17. https://doi. org/10.1111/j.1365-313X.2005.02366.X.

94. Uppalapati SR, Ishiga Y, Wangdi T, Urbanczyk-Wochniak E, Ishiga T, Mysore KS, et al. Pathogenicity of Pseudomonas syringae pv. Tomato on tomato seedlings: phenotypic and gene expression analyses of the virulence function of coronatine. Mol. Plant Microbe Interact. 2008;21(4):383-95. https://doi.org/10.1094/MPMl-21-4-0383.

95. van der Knaap E, Kim JH, Kende $\mathrm{H}$. A novel gibberellin-induced gene from rice and its potential regulatory role in stem growth. Plant Physiol. 2000; 122(3):695-704. https://doi.org/10.1104/pp.122.3.695.

96. Wang X, Elling AA, Li X, Li N, Peng Z, He G, et al. Genome-wide and organspecific landscapes of epigenetic modifications and their relationships to mRNA and small RNA transcriptomes in maize. Plant Cell. 2009;21(4):105369. https://doi.org/10.1105/tpc.109.065714.

97. Wang Y, Li J. Molecular basis of plant architecture. Annu Rev Plant Biol. 2008;59(1):253-79. https://doi.org/10.1146/annurev.arplant.59.032607.092902.

98. Wasternack C, Hause B. Jasmonates: biosynthesis, perception, signal transduction and action in plant stress response, growth and development. An update to the 2007 review in annals of botany. Ann Bot. 2013;111(6): 1021-58. https://doi.org/10.1093/aob/mct067.

99. Wei X, Zhang M, Li Z, Duan L. Effect of coronatine on internode elongation and yield characters of maize. Sci Technol Rev. 2011;29:63-7 (in chinese). https://doi.org/10.3981/j.issn.1000-7857.2011.20.011.

100. Weiler EW, Kutchan TM, Gorba T, Brodschelm W, Niesel U, Bublitz F. The Pseudomonas phytotoxin coronatine mimics octadecanoid signalling molecules of higher plants. FEBS Lett. 1994;345(1):9-13. https://doi.org/10.1 016/0014-5793(94)00411-0.

101. Winkler RG, Freeling M. Physiological genetics of the dominant gibberellinnonresponsive maize dwarfs, Dwarf8 and Dwarf9. Planta. 1994;193:341-8.

102. Winkler RG, Helentjaris T. The maize Dwarf3 gene encodes a cytochrome P450-mediated early step in gibberellin biosynthesis. Plant Cell. 1995;7: 1307-17.

103. Xiao W, Yang Y, Yu J. ZmNST3 and ZmNST4 are master switches for secondary wall deposition in maize (Zea mays L.). Plant Sci. 2018;266:83-94. https://doi.org/10.1016/j.plantsci.2017.03.012

104. Xie Z, Duan L, Li Z, Wang X, Liu X. Dose-dependent effects of coronatine on cotton seedling growth under salt stress. J Plant Growth Regul. 2015;34(3): 651-64. https://doi.org/10.1007/s00344-015-9501-1.

105. Xu C, Gao Y, Tian B, Ren J, Meng Q, Wang P. Effects of EDAH, a novel plant growth regulator, on mechanical strength, stalk vascular bundles and grain yield of summer maize at high densities. Field Crops Res. 2017;200:71-9. https://doi.org/10.1016/j.fcr.2016.10.011.

106. Xue J, Gao S, Fan Y, Li L, Ming B, Wang K, et al. Traits of plant morphology, stalk mechanical strength, and biomass accumulation in the selection of lodging-resistant maize cultivars. Eur J Agron. 2020;117:126073. https://doi. org/10.1016/j.eja.2020.126073.

107. Xue J, Zhao Y, Gou L, Shi Z, Yao M, Zhang W. How high plant density of maize affects basal internode development and strength formation. Crop Sci. 2016;56(6):3295-306. https://doi.org/10.2135/cropsci2016.04.0243.

108. Yamaguchi S. Gibberellin metabolism and its regulation. Annu Rev Plant Biol. 2008;59(1):225-51. https://doi.org/10.1146/annurev.arplant.59.032607. 092804.

109. Yang C, Powell CA, Duan Y, Ancona V, Huang J, Zhang M. Transcriptomic analysis reveals root metabolic alteration and induction of huanglongbing resistance by sulphonamide antibiotics in huanglongbing-affected citrus plants. Plant Pathol. 2020;69(4):733-43. https://doi.org/10.1111/ppa.13154.

110. Yang DL, Yao J, Mei CS, Tong XH, Zeng $\sqcup$, Li Q, et al. Plant hormone jasmonate prioritizes defense over growth by interfering with gibberellin signaling cascade. Proc Natl Acad Sci U S A. 2012;109(19):E1192-200. https://doi.org/10.1073/pnas.1201616109.

111. Yang H, Liu J, Wen X, Lu C. Molecular mechanism of photosystem I assembly in oxygenic organisms. Biochim Biophys Acta. 2015;1847(9):83848. https://doi.org/10.1016/j.bbabio.2014.12.011.

112. Ye D, Zhang Y, Al-Kaisi M, Duan L, Zhang M, Li Z. Ethephon improved stalk strength associated with summer maize adaptations to environments differing in nitrogen availability in the North China plain. J Agric Sci. 2016; 154(6):960-77. https://doi.org/10.1017/S0021859615000829.

113. Yeung KY, Haynor DR, Ruzzo WL. Validating clustering for gene expression data. Bioinformatics. 2001;17(4):309-18. https://doi.org/10.1093/bioinforma tics/17.4.309.

114. Yi F, Gu W, Chen J, Song N, Gao X, Zhang X, et al. High temporal-resolution Transcriptome landscape of early maize seed development. Plant Cell. 2019; 31(5):974-92. https://doi.org/10.1105/tpc.18.00961.

115. Young SA, Park SK, Rodgers C, Mitchell RE, Bender CL. Physical and functional characterization of the gene cluster encoding the polyketide phytotoxin coronatine in Pseudomonas syringae pv. glycinea. J Bacteriol. 1992;174(6):1837-43. https://doi.org/10.1128/JB.174.6.1837-1843.1992.

116. Zhang J, Simmons C, Yalpani N, Crane V, Wilkinson H, Kolomiets M. Genomic analysis of the 12-oxo-phytodienoic acid reductase gene family of Zea mays. Plant Mol Biol. 2005;59(2):323-43. https://doi.org/10.1007/s11103005-8883-z.

117. Zhang Q, Cheetamun R, Dhugga KS, Rafalski JA, Tingey SV, Shirley NJ, et al. Spatial gradients in cell wall composition and transcriptional profiles along elongating maize internodes. BMC Plant Biol. 2014;14(1):27. https://doi.org/1 $0.1186 / 1471-2229-14-27$.

118. Zhang $X$, Zheng L, Zhang $H$, Huang $X$, Liu Y, Zhang J, et al. Insights into the BR2/PGP1-mediated patterns for shoot and root growth in maize early seedling development by comparative transcriptome sequencing. J Plant Biol. 2019a;62(3):217-28. https://doi.org/10.1007/s12374-018-0394-y.

119. Zhang Y, Wang Y, Ye D, Wang W, Qiu X, Duan L, et al. Ethephon improved stalk strength of maize (Zea mays $L$.) mainly through altering internode morphological traits to modulate mechanical properties under field conditions. Agronomy. 2019b;9:186.

120. Zhang Y, Wang Y, Ye D, Xing J, Duan L, Li Z, et al. Ethephon-regulated maize internode elongation associated with modulating auxin and gibberellin signal to alter cell wall biosynthesis and modification. Plant Sci. 2020a;290:110196. https://doi.org/10.1016/j.plantsci.2019.110196.

121. Zhang J, Zhang Y, Xing J, Yu H, Zhang R, Chen Y, et al. Introducing selective agrochemical manipulation of gibberellin metabolism into a cereal crop. Nat. Plants. 2020b;6(2):67-72. https://doi.org/10.1038/s41477-019-0582-x.

122. Zhang Z, Li X, Zhang C, Zou H, Wu Z. Isolation, structural analysis, and expression characteristics of the maize nuclear factor $Y$ gene families. Biochem Biophys Res Commun. 2016;478(2):752-8. https://doi.org/10.1016/j. bbrc.2016.08.020.

123. Zhao G, Fu J, Wang G, Ma P, Wu L, Wang J. Gibberellin-induced mesocotyl elongation in deep-sowing tolerant maize inbred line 3681-4. Plant Breed. 2010;129(1):87-91. https://doi.org/10.1111/j.1439-0523.2009.01658.x.

124. Zhou Y, Liu Y, Peng C, Li X, Zhang M, Tian X, et al. Coronatine enhances drought tolerance in winter wheat by maintaining high photosynthetic performance. J Plant Physiol. 2018;228:59-65. https://doi.org/10.1016/j. jplph.2018.05.009

125. Zimmermann R, Sakai H, Hochholdinger F. The gibberellic acid stimulatedlike gene family in maize and its role in lateral root development. Plant Physiol. 2010;152(1):356-65. https://doi.org/10.1104/pp.109.149054.

\section{Publisher's Note}

Springer Nature remains neutral with regard to jurisdictional claims in published maps and institutional affiliations.

Ready to submit your research? Choose BMC and benefit from:

- fast, convenient online submission

- thorough peer review by experienced researchers in your field

- rapid publication on acceptance

- support for research data, including large and complex data types

- gold Open Access which fosters wider collaboration and increased citations

- maximum visibility for your research: over $100 \mathrm{M}$ website views per year

At $\mathrm{BMC}$, research is always in progress.

Learn more biomedcentral.com/submission 